\title{
Drought severity-duration-frequency curves: a foundation for risk assessment and planning tool for ecosystem establishment in post-mining landscapes
}

\author{
D. Halwatura ${ }^{1}$, A. M. Lechner ${ }^{2,3}$, and S. Arnold ${ }^{1}$ \\ ${ }^{1}$ Centre for Mined Land Rehabilitation, Sustainable Minerals Institute, the University of Queensland, Brisbane, Australia \\ ${ }^{2}$ Centre for Social Responsibility in Mining, Sustainable Minerals Institute, the University of Queensland, Brisbane, Australia \\ ${ }^{3}$ Centre for Environment, University of Tasmania, Hobart, Australia
}

Correspondence to: D. Halwatura (d.halwatura@uq.edu.au)

Received: 10 April 2014 - Published in Hydrol. Earth Syst. Sci. Discuss.: 13 May 2014

Revised: 28 January 2015 - Accepted: 30 January 2015 - Published: 26 February 2015

\begin{abstract}
Eastern Australia has considerable mineral and energy resources, with areas of high biodiversity value co-occurring over a broad range of agro-climatic environments. Lack of water is the primary abiotic stressor for (agro)ecosystems in many parts of eastern Australia. In the context of mined land rehabilitation quantifying the severityduration-frequency (SDF) of droughts is crucial for successful ecosystem rehabilitation to overcome challenges of early vegetation establishment and long-term ecosystem resilience.

The objective of this study was to quantify the SDF of short-term and long-term drought events of 11 selected locations across a broad range of agro-climatic environments in eastern Australia by using three drought indices at different timescales: the Standardized Precipitation Index (SPI), the Reconnaissance Drought Index (RDI), and the Standardized Precipitation-Evapotranspiration Index (SPEI). Based on the indices we derived bivariate distribution functions of drought severity and duration, and estimated the recurrence intervals of drought events at different timescales. The correlation between the simple SPI and the more complex SPEI or RDI was stronger for the tropical and temperate locations than for the arid locations, indicating that SPEI or RDI can be replaced by SPI if evaporation plays a minor role for plant available water (tropics). Both short-term and long-term droughts were most severe and prolonged, and recurred most frequently in arid regions, but were relatively rare in tropical and temperate regions.
\end{abstract}

Our approach is similar to intensity-duration-frequency (IDF) analyses of rainfall, which are crucial for the design of hydraulic infrastructure. In this regard, we propose to apply SDF analyses of droughts to design ecosystem components in post-mining landscapes. Together with design rainfalls, design droughts should be used to assess rehabilitation strategies and ecological management using drought recurrence intervals, thereby minimising the risk of failure of initial ecosystem establishment due to ignorance of fundamental abiotic and site-specific environmental barriers, such as flood and drought events.

\section{Introduction}

Eastern Australia holds vast mineral and energy resources of economic importance and internationally significant biodiversity (Williams et al., 2002; Myers et al., 2000) occurs over a broad range of agro-climatic environments (Hutchinson et al., 2005; Woodhams et al., 2012). There are also extensive areas of cropping and grazing such as in the Brigalow Belt Bioregion (Arnold et al., 2013) and the wheatbelt regions around Kingaroy and Wagga Wagga (Woodhams et al., 2012) (Table 1, Fig. 1). Lack of water availability is a critical factor for the mining industry, agriculture and biodiversity. For example, water deficit reduces agricultural productivity and increases the risk of failure of ecosystem rehabilitation. Likewise, flooding affects mining as a result of soil erosion in rehabilitation areas or flooded mine sites pre- 


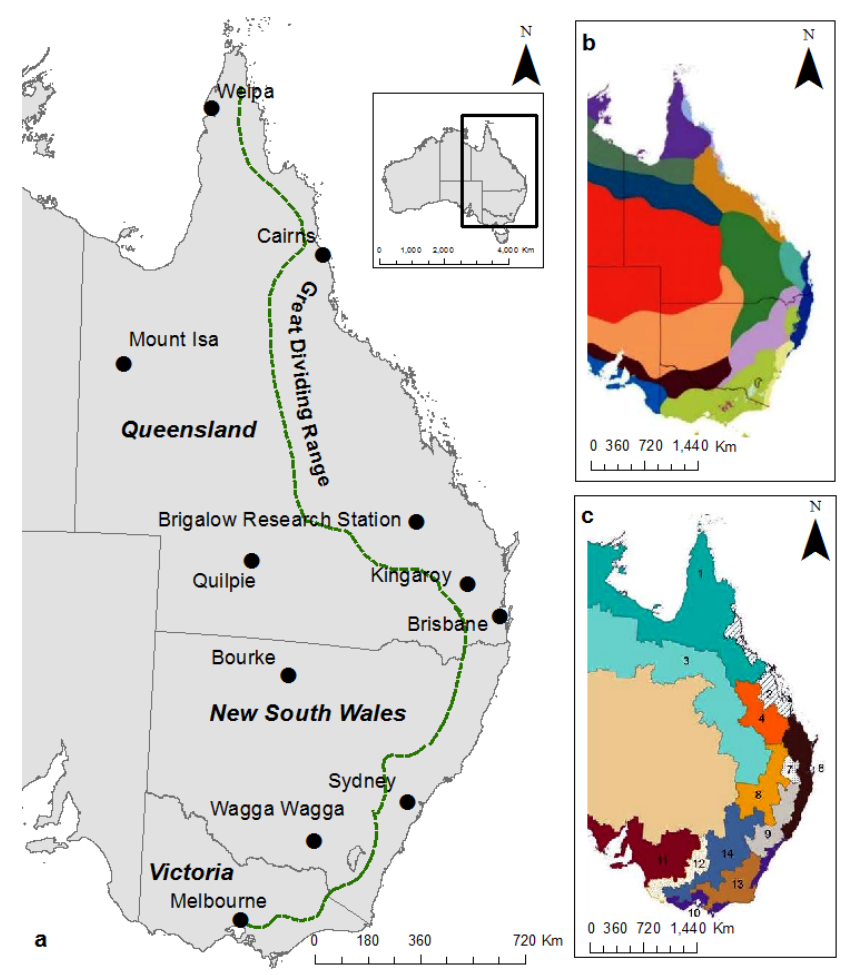

Figure 1. (a) Selected locations of interest with boundaries of (b) agro-climatic classes (Hutchinson et al., 2005) and (c) Australian agricultural environments (Woodhams et al., 2012).

venting production. For some of the agro-climatic regions in eastern Australia, the lack of water is the primary abiotic stressor for (agro)ecosystems throughout the year, whereas for others water availability is at least seasonally limited (Table 1). In the past century, regions across Australia have regularly experienced periods of water deficit (Murphy and Timbal, 2008). Approximately one-third of Australia is arid with rainfall of less than $250 \mathrm{~mm}$ per year, and another one-third is semi-arid (250-500 $\left.\mathrm{mm} \mathrm{yr}^{-1}\right)$. There are few areas where rainfall exceeds evaporation on an annual basis (Bell, 2001). Drought events are distributed diversely with regard to their duration, severity, and frequency of occurrence over the continent.

Droughts and associated limitations in plant available water determine plant distribution in response to climatic conditions in post-mining landscapes. Ecosystem attributes such as the distribution of native tropical species (Engelbrecht et al., 2007; Kuster et al., 2013), the structure and functioning of forests (Zhang and Jia, 2013; Vargas et al., 2013), biodiversity and ecosystem resilience (Brouwers et al., 2013; Lloret, 2012; Jongen et al., 2013), and primary productivity and respiration of vegetation (Shi et al., 2014) are sensitive to the occurrence of drought events. In the context of mined land rehabilitation, droughts also play a critical role for the early establishment of plants (Nefzaoui and Ben Salem, 2002; Gardner and Bell, 2007) and long-term resilience of novel
(Doley et al., 2012; Doley and Audet, 2013) and/or native ecosystems on post-mining land (Bell, 2001). Across the life span of plants due to their under-developed root system, juvenile vegetation such as seeds, seedlings, and pre-mature rather than climax vegetation is especially vulnerable to lack of water availability (Jahantab et al., 2013; Craven et al., 2013; Arnold et al., 2014a). For climax vegetation, however, medium to long-term drought (greater than 9 months) periods rather than short-term droughts (3 months or less) may critically impact rehabilitation by altering plant communities' species composition (Mariotte et al., 2013; Ruffault et al., 2013).

Droughts are usually characterised through the use of indices, which vary in complexity and data needs. Meteorological or climatological droughts are the simplest and are based on the characterisation of anomalies in rainfall conditions (Anderegg et al., 2013). For meteorological droughts, standardised drought indices such as the Standardized Precipitation Index (SPI), Reconnaissance Drought Index (RDI) and Standardized Precipitation-Evapotranspiration Index (SPEI) provide the means to quantifying the duration and severity, and eventually the frequency or recurrence of drought events (McKee et al., 1993; Tsakiris and Vangelis, 2005; VicenteSerrano et al., 2010). Although there are numerous comparative studies of drought indices in certain climatic regions such as the Mediterranean, (Paulo et al., 2012; Livada and Assimakopoulos, 2007), the Carpathian region (Spinoni et al., 2013), and other arid locations (Peel et al., 2007; Zarch et al., 2011), none of these indices apply universally to any climate region and it is best for land managers to use a range of drought indices at various temporal scales (Heim, 2002; Spinoni et al., 2013). In many parts of the world evaporation data are unavailable or incomplete and simple rainfall indices such as SPI are most commonly used. In this study, we compare SPI with RDI at the 3-month timescale and SPI and SPEI at the 12-month timescale to determine the difference between using SPI with more complex indices that incorporate evaporation in different climatic regions.

Drought periods can be characterised from a few hours (short-term) to millennia (long-term) depending on the ecological or socio-economic question being addressed. The time lag between the beginning of a period of water scarcity and its impact on socio-economic and/or environmental assets is referred to as the timescale of a drought (VicenteSerrano et al., 2013). There are three timescales for which drought indices are usually calculated; short-term droughts are 3 months or less; medium-term droughts are between 4 to 9 months; and long-term droughts are 12 months or more (Zargar et al., 2011). Short-term droughts have an impact on water availability in the vadose zone (National Drought Mitigation Center, 2014; Zargar et al., 2011), while long-term droughts also affect surface and ground water resources (National Drought Mitigation Center, 2014; Zargar et al., 2011).

Of key importance for land managers planning for drought events of any timescale is characterising the return period or 


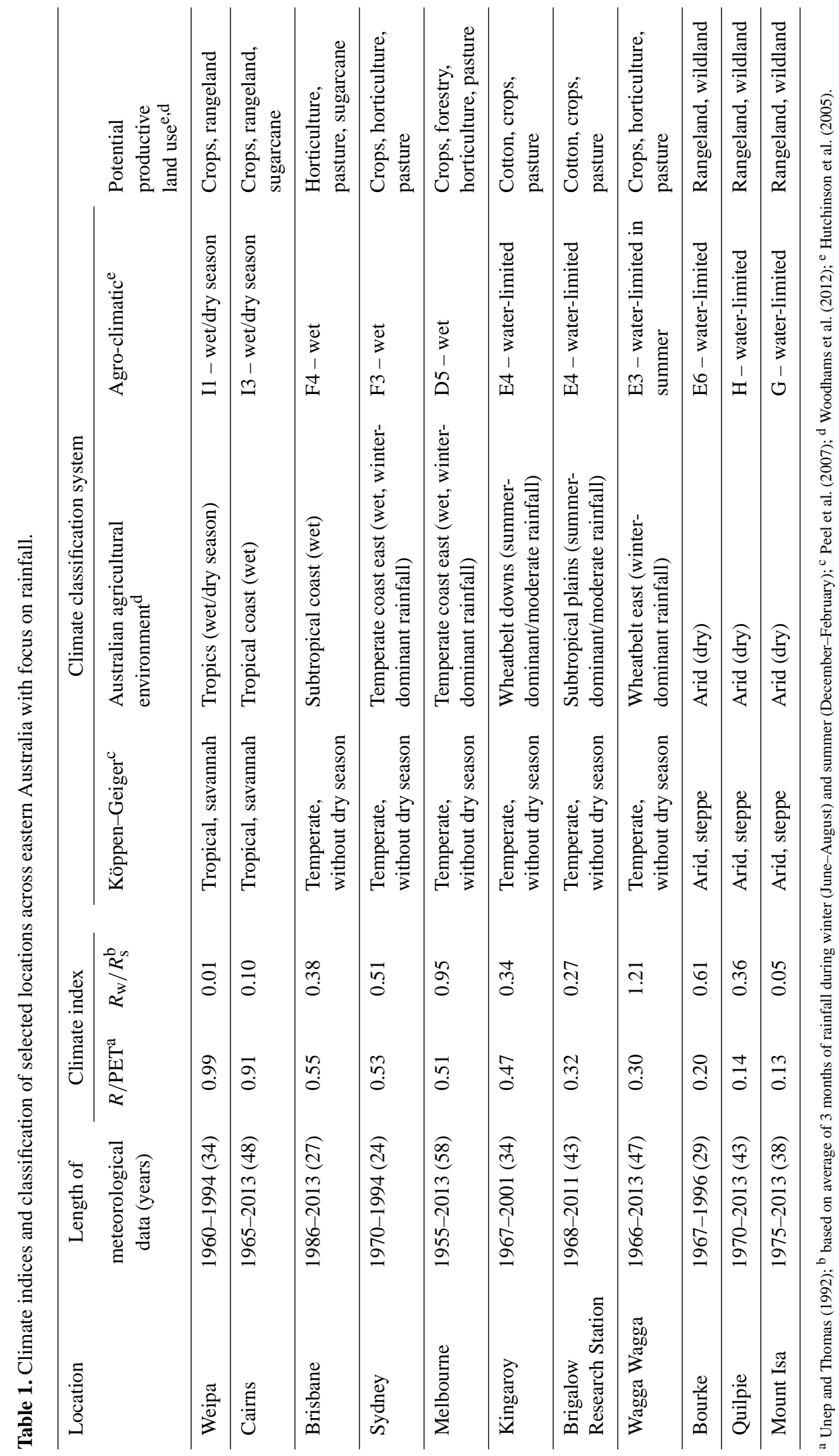


frequency of occurrence of rainfall and drought events. The recurrence interval is defined as the average inter-occurrence time of any geophysical phenomena and is calculated with long-term time series data (Loaiciga and Mariño, 1991). Recurrence intervals of rainfall events greater than the average are commonly used by engineers to derive intensityduration-frequency (IDF) design estimates for building hydraulic infrastructure such as roofs, culverts, stormwater drains, bridges or water dams (Chebbi et al., 2013; Kuo et al., 2013; Hailegeorgis et al., 2013). IDF design rainfalls are crucial for estimating the risk of hydraulic infrastructure failure and for maximising infrastructure efficiencies (Smithers et al., 2002). Similar to the concept of IDF design rainfall, which aims to quantify the recurrence interval of rainfall events based on their intensity and duration, we apply the same concept to quantify the recurrence intervals of droughts based on their severity and duration, and refer to this as severity-duration-frequency (SDF) design drought. SDF curves have been used to derive drought variables (severity, duration, frequency of occurrence) in different climatic regions (Shiau, 2006; Shiau et al., 2012; Lee and Kim, 2012; Todisco et al., 2013; Mirabbasi et al., 2012) but have rarely been used in ecology, and never been used in relation to rehabilitation and restoration. While IDF design rainfalls are a well-established tool in civil engineering and hydrology, we believe SDF design drought could be used in a similar way to assess the risk of ecosystem rehabilitation failure due to droughts.

This approach contrasts current climate classification methods (Table 1) such as the classification of the Australian agricultural environments (Woodhams et al., 2012) or the Australian agro-climatic classes (Hutchinson et al., 2005) that are used for the management of agricultural land (Audet et al., 2013). These classifications are based on average climatic conditions and may not be adequate for the management of early vegetation re-establishment in post-mining landscapes (Audet et al., 2012, 2013) because of the vulnerability of vegetation to drought events. Although droughts play a critical role in post-mining land restoration in eastern Australia, so far methods for quantifying the frequency of drought events have been rarely applied to assess the risk of failure of ecosystem rehabilitation. In the perspective of mined land rehabilitation, specific metrics of site climate or seasonality are surprisingly rare (Audet et al., 2013).

The objective of our study is to quantify the severity, duration, and frequency (SDF) of short-term and long-term drought events at selected locations across a broad range of agro-climatic environments in eastern Australia (Table 1, Fig. 1). Eastern Australia makes a very good case study for this kind of research as there are a wide range of climates in which data has been gathered using a consistent method by one agency. While other studies assessed the SDF characteristics at locations with the same climate in Iran (Shiau and Modarres, 2009; Shiau et al., 2012), no such investigations are known for any climatic region in Australia, for the same climate or different climates.

We characterised droughts using the RDI and SPEI for 3and 12-month timescales respectively, and compared these indices with the SPI at the same timescales. We then linked the univariate distributions of severity and duration calculated with the drought indices to form bivariate distribution functions and estimated the recurrence intervals of droughts. Please note that since the estimated recurrence intervals are based on historic rainfall and evaporation data, our results are descriptive rather than predictive. Nevertheless, our findings are crucial to discuss the potential of design droughts to be applied as a management tool to overcome the challenges of early vegetation establishment and long-term ecosystem resilience in post-mining landscapes. This is because frequency patterns of drought events are ignored in any current rehabilitation guidelines and industry plans, where long-term average rainfall is the only parameter upon which management decisions are based on (Audet et al.,2013).

\section{Materials and methods}

Estimating SDF curves involves uncertainties associated with the length of the observed rainfall data, the applied drought index, the probability distribution functions used to fit the observed severity and duration, and the estimated copula parameter (Hu et al., 2014). To overcome these uncertainties we tested the applicability of drought indices for locations in different climatic regions by calculating the correlation of three selected drought indices. Likewise, we used the best fitted probability distribution functions and copula for each site. A flow chart of the processing steps is depicted in a schematic diagram (Fig. 2).

We selected 11 sites, for which historical observations of monthly rainfall and evaporation (ranging from 30-60 years) (Table 1) were most comprehensive (more than $97 \%$ coverage) (i.e. longest and most complete - more than $97 \%$ coverage) across eastern Australia (Bureau of Meteorology, 2013). The selected locations covered a broad range of climate classes and environments across eastern Australia (Table 1, Fig. 1).

For each site we compared the simple SPI with the more complex RDI and SPEI drought indices. Amongst the three indices, the SPI is the most widely used and simplest drought index, because it is solely based on long-term rainfall for any period of interest (McKee et al., 1993; Guttman, 1999). However, SPI may not adequately characterise drought events, because it does not incorporate other meteorological data (Vicente-Serrano et al., 2010; Mishra and Singh, 2010). Both the RDI and SPEI integrate potential evaporation and thereby better represent the local water balance (Tsakiris, 2004; Tsakiris and Vangelis, 2005; Tsakiris et al., 2007; Vangelis et al., 2013). 


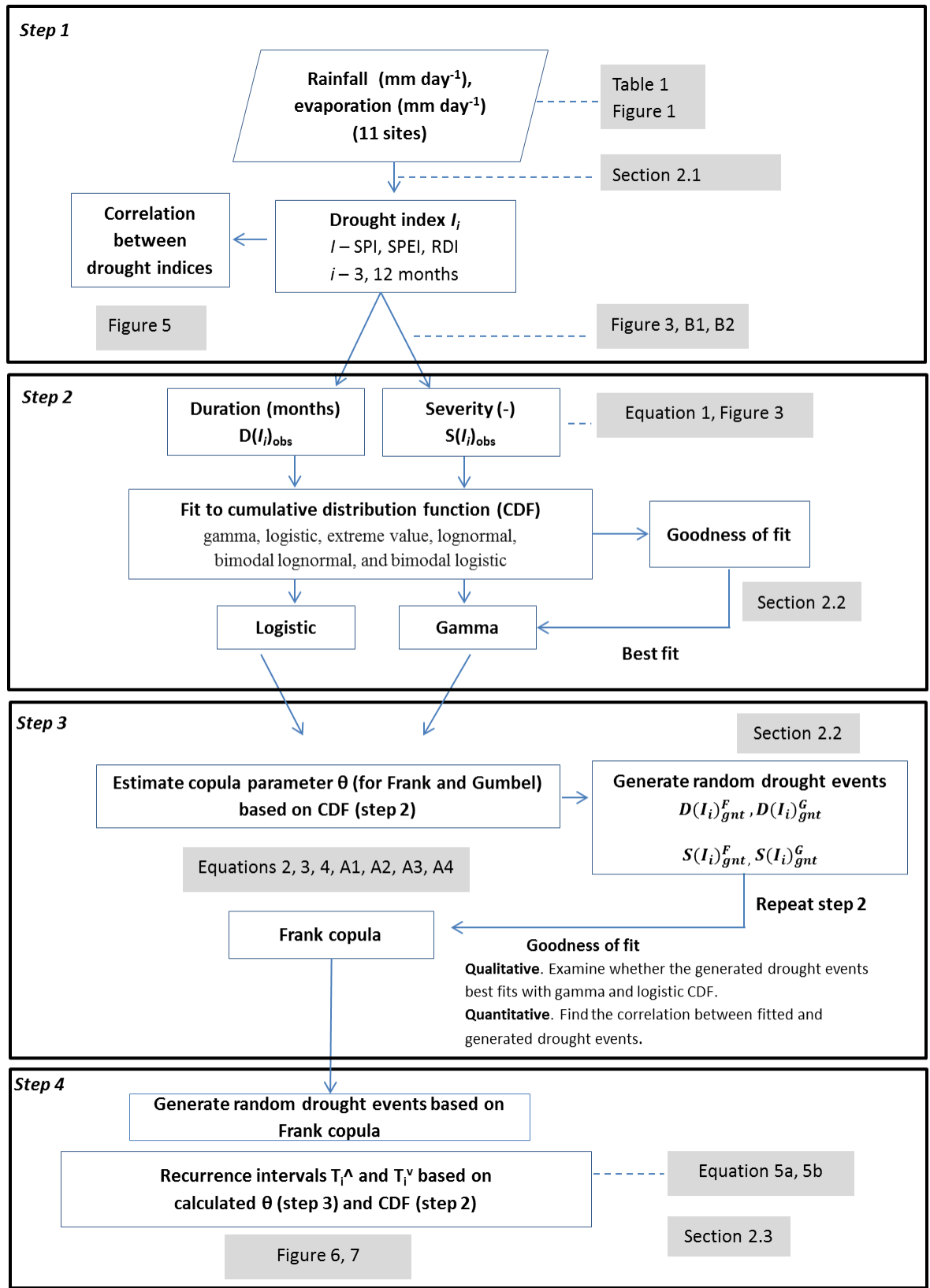

F-Frank copula, G-Gumbel copula, gnt-generated

Figure 2. Schematic diagram of steps applied to estimate recurrence intervals of drought events. See Sect. 2 for further details. Step 1: calculate drought index based on monthly rainfall (SPI) and evaporation (RDI, SPEI). Step 2: fit cumulative distribution function (CDF) to estimated drought duration and severity. Step 3: estimate copula parameter based on CDFs. Step 4: calculate recurrence intervals based on CDFs of univariate (severity, duration) distributions and bivariate joint distribution (copula).

The drought indices are calculated using monthly values of rainfall and/or potential evaporation. Amongst the two indices which incorporate potential evaporation, the RDI plays a strong role in detecting maximum drought severities at the medium timescale ( 3 to 6 months) (Banimahd and Khalili, 2013), while the SPEI plays a strong role in detecting annual drought events by identifying the hydrological summer drought events (Egidijus et al., 2013). There is evidence that SPI overestimates small rainfall scarcity even if excessive rainfall occurs just before the period of interest (Kim et al., 2009). Also for humid climates, there is a good correspondence between the computed $\mathrm{SPI}_{3}$ and $\mathrm{RDI}_{3}$ (Khalili et al., 2011). For Mediterranean climate, SPI and SPEI at 9- and 12month timescales are well correlated (Paulo et al., 2012), and 
in the Carpathian region SPI, SPEI, and RDI are highly comparable over annual periods (Spinoni et al., 2013). In arid regions, the correlation of SPI and RDI is more considerable at the 3-, 6-, and 9-monthly timescale (Peel et al., 2007; Zarch et al., 2011).

\subsection{Step 1: calculate drought indices}

The SPI is derived by fitting a probability distribution to the rainfall record and then transforming that to a normal distribution, so that mean and standard deviation of the SPI are zero and one. Positive or negative values of the SPI represent rainfall conditions greater or smaller than average rainfall, respectively (McKee et al., 1993). RDI and SPEI are based on the SPI calculation procedure, except the two indices use the quotient or difference of precipitation and potential evaporation, respectively (Tsakiris et al., 2007; Vicente-Serrano et al., 2010). Equations for the RDI and SPEI are presented in Appendix A. We applied two correlation coefficients to assess the correlations between $\mathrm{SPI}_{3}$ and $\mathrm{RDI}_{3}$, and $\mathrm{SPI}_{12}$ with $\mathrm{SPEI}_{12}$ (step 1 in Fig. 2): Kendall's $\tau$ to assess the number of concordances and discordances in paired variables $\left(\mathrm{RDI}_{3}\right.$ and $\mathrm{SPI}_{3}, \mathrm{SPEI}_{12}$ and $\mathrm{SPI}_{12}$ ), and Pearson's $r$ to measure linear correlation.

\subsection{Step 2: bivariate distribution of drought severity and duration}

For each location, we used the estimated drought indices (SPI, RDI, SPEI), hereafter collectively referred to as $I$, to quantify duration $D$ and severity $S$ (McKee et al., 1993; Vicente-Serrano et al., 2010; Tsakiris and Vangelis, 2005). The duration of any drought was defined as the period of rainfall deficit, i.e. the cumulative time of negative $I$ values preceded and followed by positive $I$ values (Fig. 3). The severity of any drought period starting at the $i$ th month was defined as

$S=\sum_{i=1}^{D}\left|-I_{i}\right|$.

We fitted the time series of $D$ and $S$ to a range of cumulative distribution functions (gamma, logistic, extreme value, lognormal, bimodal lognormal, and exponential) and used the function with the best fit for further investigations (step 2 in Fig. 2). The coefficient of determination and $95 \%$ confidence levels were calculated for each distribution in order to select the best distribution.

\subsection{Step 3: estimate copula parameter}

We used copulas to link the univariate probability distributions of $D$ and $S$ to construct a bivariate joint distribution of $D$ and $S$ (Shiau and Modarres, 2009; Sklar, 1959) (step 3 in Fig. 2). As the choice of copula can be very different from one climate region to another (Khedun et al., 2013) the

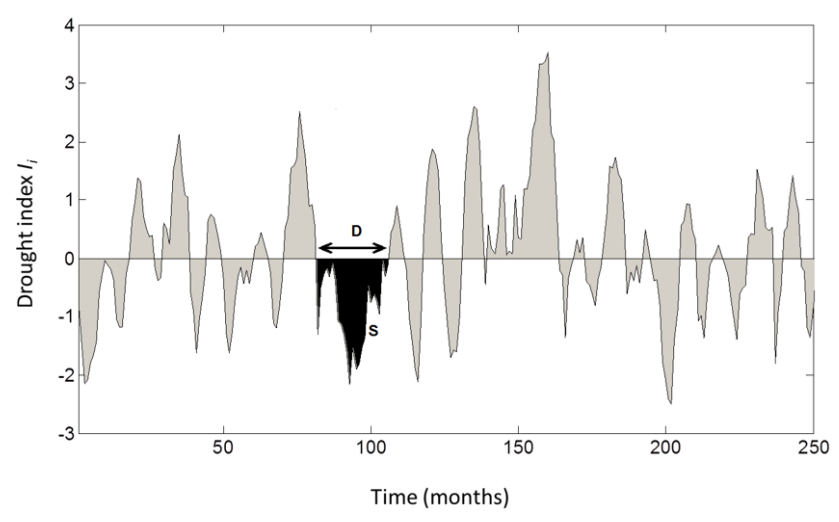

Figure 3. Concept of severity $S$ and duration $D$ of a drought event quantified with drought index $I_{i}$, where $i$ refers to any timescale of interest.

present study focused on the Frank and Gumbel copulas (Appendix B), as they perform best when analysing the bivariate drought dependence structure of drought variables such as severity and duration (Ganguli and Reddy, 2012; Reddy and Ganguli, 2012; Shiau, 2006; Lee et al., 2013; Wong et al., 2010; Zhang et al., 2011). The conditional cumulative distribution function $F_{\mathrm{S} \mid \mathrm{D}}(s \mid d)$ which relates to the joint cumulative distribution function (JCDF) of drought severity and duration $F_{\mathrm{S}, \mathrm{D}}(s, d)$ and the cumulative distribution function (CDF) of drought duration $F_{\mathrm{D}}(d)$ is given by the following relationship (Shiau and Modarres, 2009):

$F_{\mathrm{S} \mid \mathrm{D}}(s \mid d)=\frac{\partial F_{\mathrm{S}, \mathrm{D}}(s, d)}{\partial F_{\mathrm{D}(d)}}$,

where $F_{\mathrm{D}}(d)$ is the CDF of drought duration, and $F_{\mathrm{S}, \mathrm{D}}(s, d)$ is the JCDF of drought severity and drought duration. The JCDF of drought severity and duration in terms of copulas is a function of univariate CDFs of duration and severity:

$F_{\mathrm{S}, \mathrm{D}}(s, d)=C\left(F_{\mathrm{S}}(s), F_{\mathrm{D}}(d)\right)$,

where $F_{\mathrm{S}}(s)$ and $F_{\mathrm{D}}(d)$ are CDFs for drought severity and duration, respectively, and $C$ is a copula function. The conditional distribution function $F_{\mathrm{S} \mid \mathrm{D}}(s \mid d)$ (Eq. 2) can also be expressed as a function of the copula (Shiau and Modarres, 2009):

$$
\begin{aligned}
F_{\mathrm{S} \mid \mathrm{D}}(s \mid d) & =\frac{\partial F_{\mathrm{S}, \mathrm{D}}(s, d)}{\partial F_{\mathrm{D}}(d)}=\frac{\partial C\left(F_{\mathrm{S}}(s), F_{\mathrm{D}}(d)\right)}{\partial F_{\mathrm{D}}(d)} \\
& =C_{F_{\mathrm{S}} \mid F_{\mathrm{D}}}\left(F_{\mathrm{S}}(s) \mid F_{\mathrm{D}}(d)\right) .
\end{aligned}
$$

We estimated the copula parameters using the inference function for margins (IFM) (Joe, 1997). The IFM comprises two separate valuation stages. First, the maximum likelihood estimation of each univariate distribution is performed, and then the copula dependence parameter is estimated to derive the joint drought duration and severity distributions (Shiau, 2006; Shiau and Modarres, 2009; Mirabbasi et al., 2012; Shiau et al., 2007). 

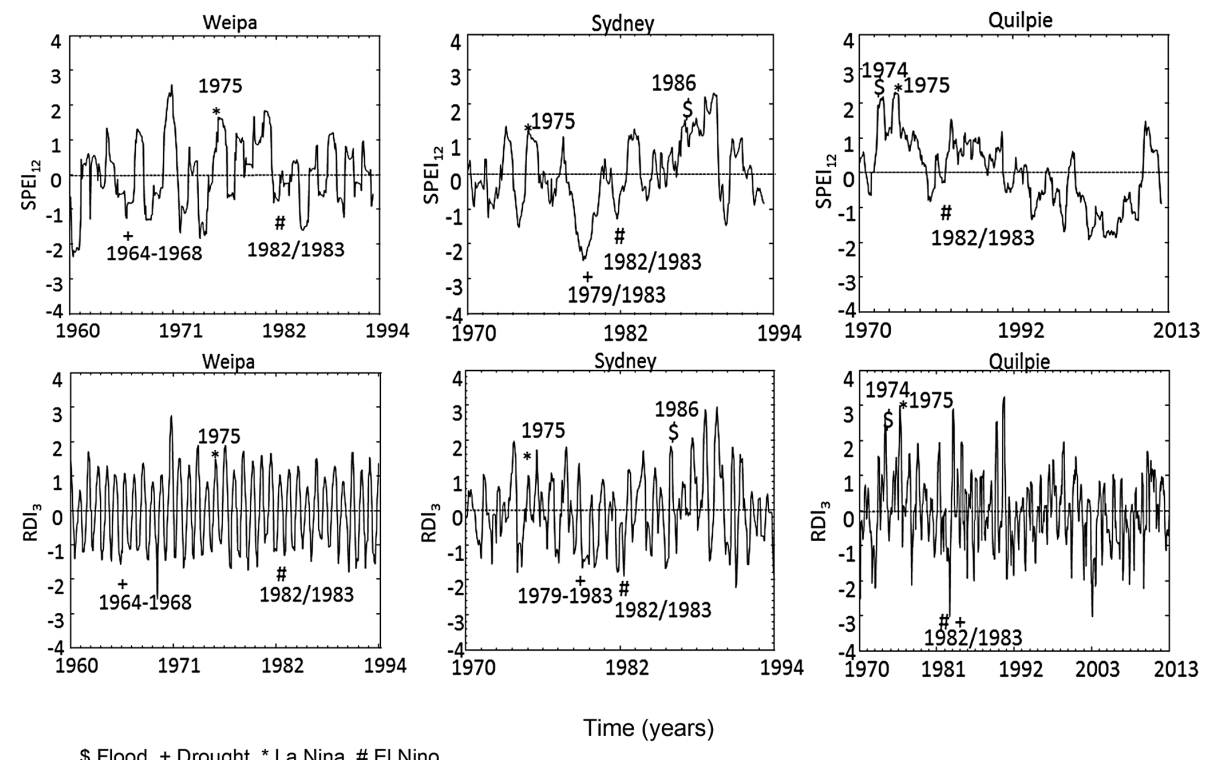

\$ Flood, + Drought, * La Nina, \# El Nino

Figure 4. Calculated $\mathrm{SPEI}_{12}$ (upper row panels) and $\mathrm{RDI}_{3}$ (lower row panels) for Weipa, Sydney and Quilpie including major weather events. The same indices are depicted for all other selected locations in Appendix B.

\subsection{Step 4: derive recurrence intervals}

We used the estimated copula parameters to generate random drought events. Severity and duration of the generated random droughts were then fitted to cumulative distribution functions in the same manner as in step 2 (Fig. 2, step 3) to test which estimated copula parameters result in a distribution that best fit the generated random drought variables. The estimated copula parameters were also assessed quantitatively through calculating the correlation between generated random drought events and the estimated gamma $(S)$ and logistic $(D)$ cumulative distribution functions.

The generated random numbers were then used to calculate the recurrence intervals. Recurrence intervals of bivariate drought events is a standard metric for hydrological frequency analysis (Yoo et al., 2013; Hailegeorgis et al., 2013) and water resources management (Shiau and Modarres, 2009; Mishra and Singh, 2010). For each location, we calculated the recurrence interval of drought events exceeding any severity $o r$ duration of interest, denoted by the logical operator " $\vee$ ":

$T_{\mathrm{I}}^{\vee}=\frac{1}{P(S \geq s \vee D \geq d)}=\frac{1}{1-C\left[F_{\mathrm{S}}(s), F_{\mathrm{D}}(d)\right]}$,

where $I$ is one of the drought indices of interest, i.e. the 12monthly $\mathrm{SPEI}_{12}$ or $\mathrm{SPI}_{12}$, or the 3-monthly $\mathrm{RDI}_{3}$ or $\mathrm{SPI}_{3}$. Alternatively, the recurrence interval of drought events exceeding any severity and duration of interest, denoted by the logical operator “ $\wedge$ ”, was calculated as

$$
\begin{aligned}
T_{\mathrm{I}}^{\wedge} & =\frac{1}{P(S \geq s \wedge D \geq d)} \\
& =\frac{1}{1-F_{\mathrm{S}}(s)-F_{\mathrm{D}}(d)+C\left[F_{\mathrm{S}}(s), F_{\mathrm{D}}(d)\right]} .
\end{aligned}
$$

For the sake of simplicity, we only present and discuss $T_{\mathrm{I}}^{\vee}$, whereas $T_{\mathrm{I}}^{\wedge}$ is presented in Appendix D.

\section{Results}

For both indices, RDI and SPEI, and all selected sites, the gamma and logistic distributions fitted best to the observed drought severity and duration, respectively $\left(R^{2}>0.98\right.$ for both variables, $p<0.05$ ) (Appendix F). Likewise, the same distributions fitted best to the drought severity and duration of the generated drought events based on the Frank rather than the Gumbel copula $\left(R^{2}>0.90, p<0.05\right)$ (Appendix F).

Based on the drought indices $\mathrm{RDI}_{3}$ and $\mathrm{SPEI}_{12}$ we detected distinct drought patterns across the selected sites at short and long-term scales, respectively. As an example of differences between tropical, temperate and arid rainfall conditions, Fig. 4 depicts calculated time series of $\mathrm{RDI}_{3}$ and $\mathrm{SPEI}_{12}$ for Weipa, Sydney and Quilpie, respectively (see Appendix $\mathrm{C}$ for rest of the sites).

Short-term droughts were most severe and prolonged in tropical Weipa and Cairns, and temperate Wagga Wagga (Table 2). However, in contrast to Wagga Wagga, the two tropical locations were characterised by distinct seasonality patterns and very low variation as indicated by the low ratio of winter to summer rainfalls (Table 1) and low coefficients of variation in severity and duration (Table 2). The highest vari- 
Table 2. Mean severity $\mu_{\mathrm{S}}$ and duration $\mu_{\mathrm{D}}$ of selected locations across eastern Australia, and corresponding coefficient of variation $\mathrm{CV}_{\mathrm{S}}$ and $\mathrm{CV}_{\mathrm{D}}$ for short-term $\left(\mathrm{RDI}_{3}\right)$ and long-term $\left(\mathrm{SPEI}_{12}\right)$ droughts.

\begin{tabular}{|c|c|c|c|c|c|c|c|c|}
\hline \multirow[t]{2}{*}{ Location } & \multicolumn{4}{|c|}{$\mathrm{RDI}_{3}$} & \multicolumn{4}{|c|}{$\mathrm{SPEI}_{12}$} \\
\hline & $\mu_{\mathrm{S}}$ & $\mathrm{CV}_{\mathrm{S}}$ & $\mu_{\mathrm{D}}$ & $\mathrm{CV}_{\mathrm{D}}$ & $\mu_{\mathrm{S}}$ & $\mathrm{CV}_{\mathrm{S}}$ & $\mu_{\mathrm{D}}$ & $\mathrm{CV}_{\mathrm{D}}$ \\
\hline Weipa & 5.2 & 0.2 & 5.8 & 0.1 & 8.4 & 1.1 & 10.4 & 0.8 \\
\hline Cairns & 4.7 & 0.4 & 6.4 & 0.3 & 9.6 & 1.3 & 12.5 & 1.0 \\
\hline Brisbane & 3.1 & 3.3 & 3.6 & 0.8 & 11.2 & 0.9 & 13.3 & 0.8 \\
\hline Sydney & 3.4 & 0.9 & 4.4 & 0.6 & 6.5 & 1.7 & 8.9 & 0.9 \\
\hline Melbourne & 4.5 & 0.7 & 5.8 & 0.5 & 14.5 & 1.9 & 18.6 & 1.6 \\
\hline Kingaroy & 2.8 & 1.2 & 3.7 & 0.8 & 7.0 & 1.1 & 8.3 & 0.8 \\
\hline Brigalow Research Station & 3.4 & 1.0 & 4.4 & 0.9 & 8.0 & 1.3 & 10.2 & 1.0 \\
\hline Wagga Wagga & 5.2 & 0.8 & 6.2 & 0.6 & 8.6 & 1.8 & 13.8 & 1.1 \\
\hline Bourke & 2.8 & 3.9 & 3.9 & 1.1 & 8.2 & 2.0 & 9.9 & 1.5 \\
\hline Quilpie & 3.5 & 1.1 & 4.6 & 0.7 & 18.8 & 2.1 & 21.8 & 1.5 \\
\hline Mount Isa & 3.8 & 0.7 & 4.9 & 0.5 & 11.1 & 1.2 & 14.4 & 0.9 \\
\hline
\end{tabular}

ation in severity was detected in arid Bourke and temperate Brisbane (Table 1).

Long-term droughts were most severe and prolonged in arid Quilpie (Table 2) and rare in temperate Melbourne. Likewise, severity and duration varied most at the two locations, together with arid Bourke. While severity and duration were moderately high in arid Mount Isa and temperate Brisbane, both parameters were low across the other selected temperate and tropical locations (Table 2).

No significant differences were detected $(p<0.05$ at $95 \%$ confidence level) between $\mathrm{RDI}_{3}$ and $\mathrm{SPI}_{3}$, and $\mathrm{SPEI}_{12}$ and $\mathrm{SPI}_{12}$ (Fig. 5 and Appendix E). Correlation between RDI/SPEI and SPI was greatest for tropical Cairns and Weipa, and lowest for arid Bourke and Quilpie (outliers in Fig. 5). Interestingly, although Mount Isa was the most arid location $(R / \mathrm{PET}=0.13$, Table 1$)$, the correlations between drought indices were relatively strong with values of 0.903 (Pearson's $r$ ) and 0.759 (Kendall's $\tau$ ) for long-term droughts.

For each location, the recurrence intervals of drought events exceeding any severity or duration of interest are depicted in Fig. 6 for short-term droughts (based on $\mathrm{RDI}_{3}$ ) and Fig. 7 for long-term droughts (based on SPEI ${ }_{12}$ ). Shortterm droughts recurred most frequently in arid Mount Isa and were relatively rare in tropical Weipa and Cairns, and temperate Sydney. For example, in Mount Isa a drought with severity of 14 or duration of 17 months ${ }^{1}$ recurred once in 50 years, whereas the same drought recurred only once in 100000 years in Weipa, 300 years in Cairns, and 100 years in Sydney (Fig. 6). Long-term droughts recurred most frequently in arid Quilpie, where droughts with severity of 18 or duration of 10 months recurred once in 2 years. In Kingaroy and Sydney, the same drought recurred only once in 4 and 5 years, respectively (Fig. 7). Interestingly, although average long-term droughts were very severe and prolonged in Mel-

\footnotetext{
${ }^{1}$ Drought events are calculated by 3 -month (short-term) and 12month (long-term) running precipitation totals (Guttman, 1999).
}

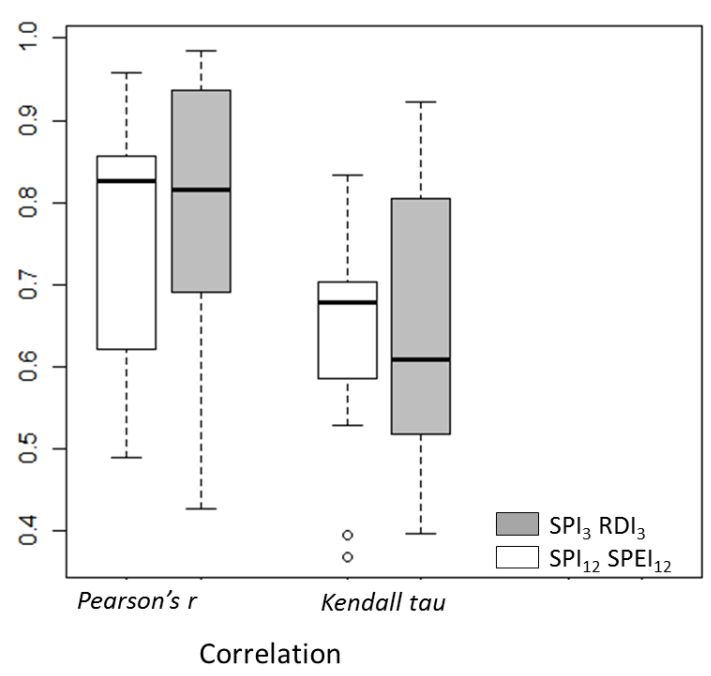

Figure 5. Correlation between $\mathrm{SPI}_{3}$ and $\mathrm{RDI}_{3}$, and $\mathrm{SPI}_{12}$ and $\mathrm{SPEI}_{12}$ based on the correlation coefficient Pearson's $r$ and Kendall's $\tau$. The outliers represent the very dry locations of Bourke and Quilpie.

bourne (Table 2), they only recurred once in 30 to 50 years. We found similar qualitative patterns in all locations for recurrence intervals of droughts exceeding any severity and duration of interest (Appendix D).

\section{Discussion}

In this study we estimated the recurrence intervals of shortand long-term droughts based on meteorological drought indices and copulas (i.e. bivariate probability distributions). For both timescales, the correlation between the simple SPI (rainfall) and the more complex SPEI or RDI (rainfall and evaporation) was much stronger for the tropical and temperate locations (e.g. Cairns, Weipa, Brigalow) than for the arid 

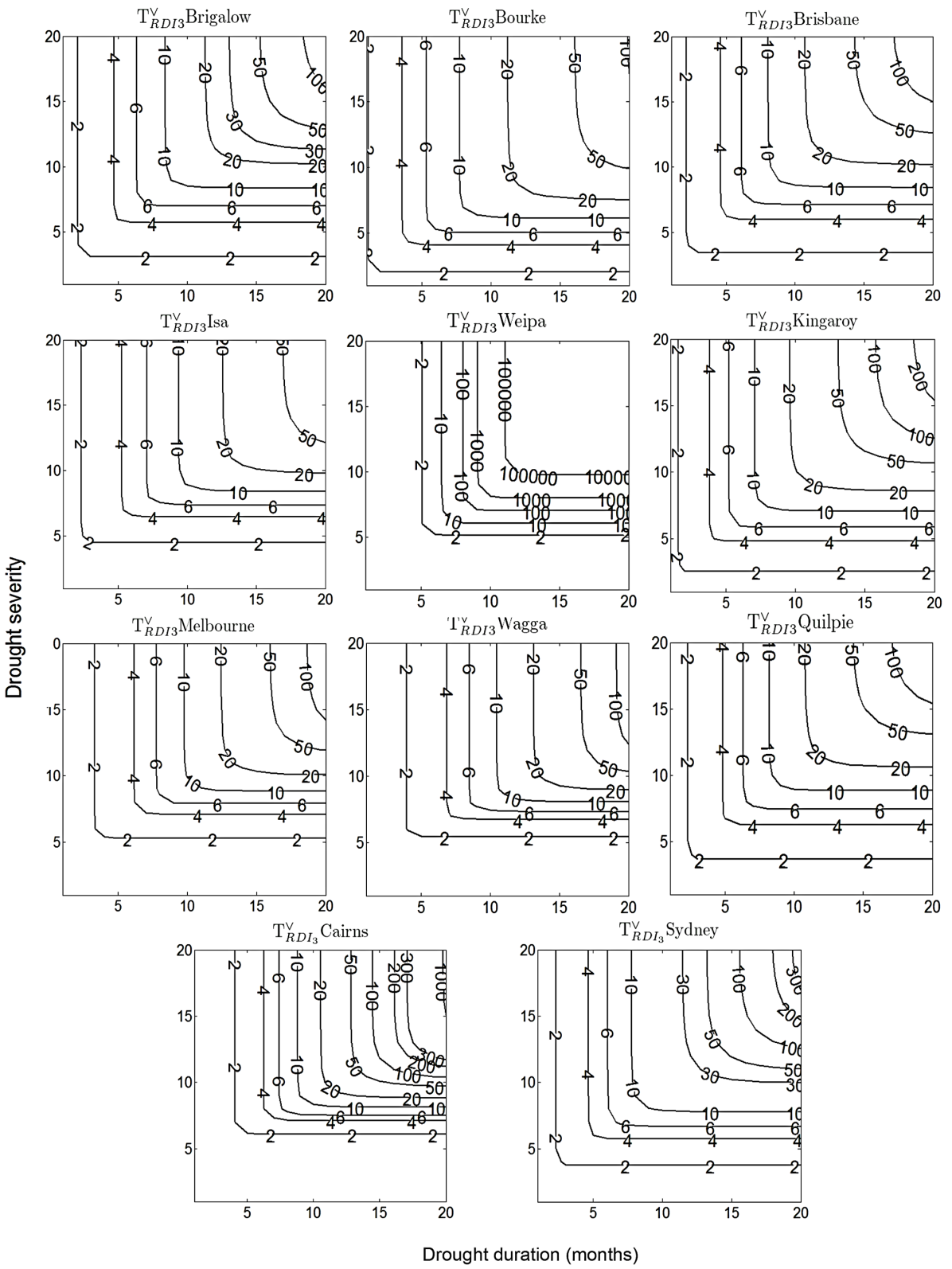

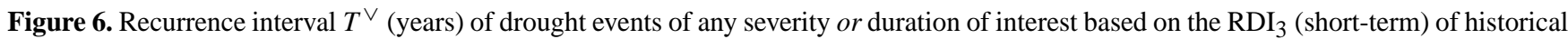
rainfall.

locations (e.g. Quilpie, Bourke, Wagga Wagga). Extending a former study on abiotic boundaries affecting ecological development of post-mining landscapes (Audet et al., 2013), our findings have critical implications for assessments of rehabilitation success.

\subsection{Implications for ecosystem rehabilitation planning}

Across eastern Australia, current post-mining land rehabilitation strategies often do not incorporate site-specific rainfall and drought metrics other than the average annual rainfall depth (Audet et al., 2013). However, regionally extreme rainfall patterns, including both intense rainfall events such as storms or cyclones and prolonged periods of water deficit (droughts), play a critical role in identifying windows of opportunity and/or challenge to the rehabilitation of earlyestablishment ecosystems (Hinz et al., 2006; Hodgkinson et al., 2010). Furthermore, Audet et al. (2013) suggested that short and long-term ecosystem rehabilitation sensitivity to climate can be effectively determined by the seasonality, regularity, and intensity of weather, combined with both median and standard deviation of periods. In particular, prolonged seasonal drought with high variation and frequently occurring intense rainfall can be used as primary characteristics 


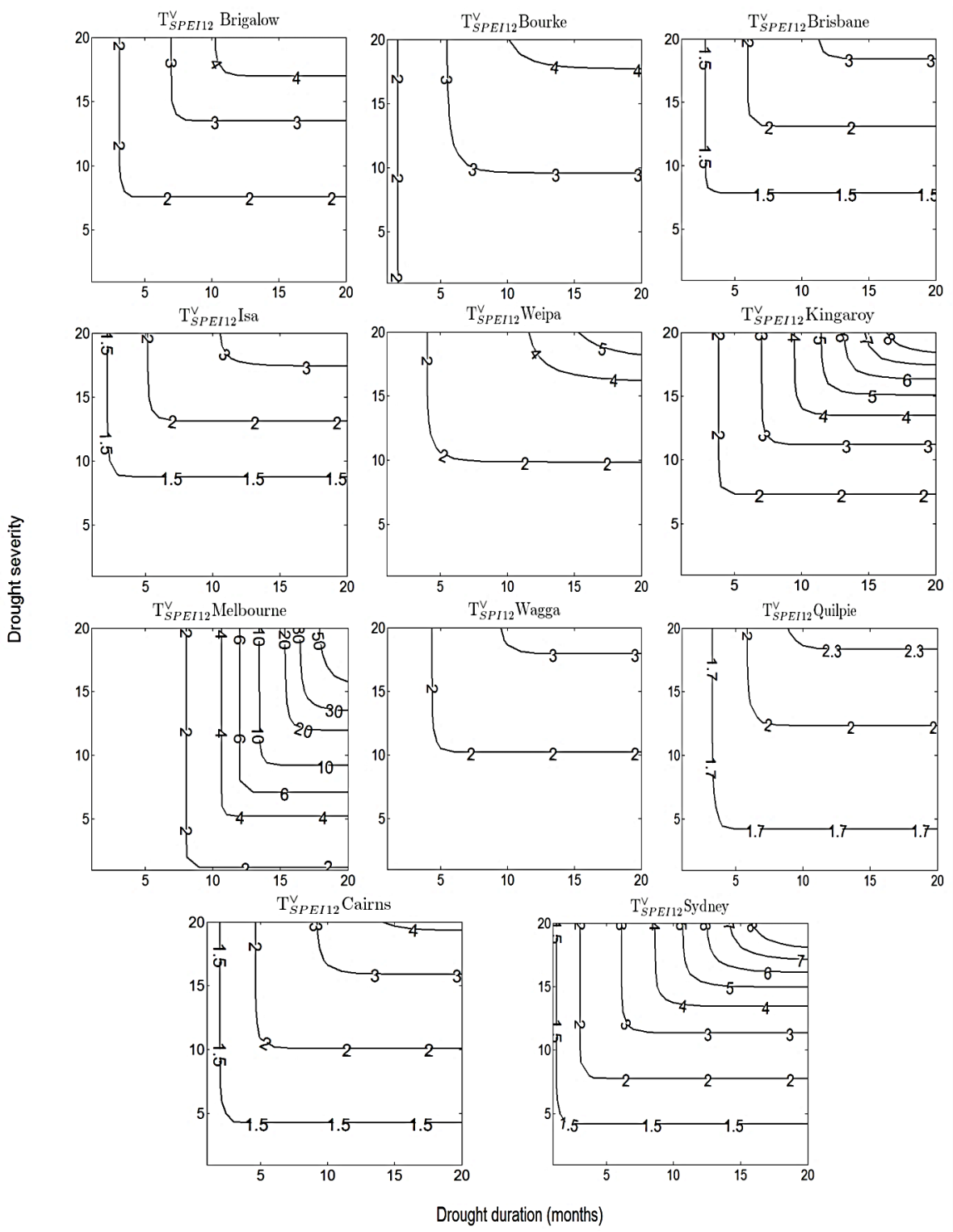

Figure 7. Recurrence interval $T^{\vee}$ (years) of drought events of any severity or duration of interest based on $\mathrm{SPEI}_{12}$ (long-term) of historical rainfall.

for determining site sensitivity, while regular rainfall and relatively short periods of water deficit are common characteristics of favourable climate conditions. Based on their findings, Audet et al. (2013) revealed how broad scale rainfall patterns outline climate boundaries that drive rehabilitation sensitivity in arid to temperate locations across eastern Australia. For example, ecosystem rehabilitation in arid regions (Mount Isa, Quilpie, and Bourke) is sensitive to climate as they have highly variable climates (long spell of droughts and high intensity rainfall), which affect the success of rehabilitation.

Commonly, the characterisation of climatic conditions is based on long-term rainfall and does not consider short and long-term drought conditions. Identifying drought and its variables are critical factors in ecosystem rehabilitation because the distribution and health of plant species are vulnerable to droughts and plant available water (Engelbrecht et al., 2007). In our study we presented two hydrological parameters describing the average recurrence intervals of shortterm and long-term droughts (Figs. 6 and 7 and Appendix D), which can be used instead of the oversimplified parameters of the median period without rain and standard deviation normally used (Audet et al., 2013).

The design drought tool proposed in this paper is an adaptation of the intensity-duration-frequency (IDF) analysis of rainfall events, a standard tool used by engineers (Hailege- 
Table 3. Management actions for addressing specific kinds of drought characteristics identified with SDF curves for the southern hemisphere.

\begin{tabular}{lll}
\hline $\begin{array}{l}\text { Management } \\
\text { domain }\end{array}$ & Management actions & $\begin{array}{l}\text { Type of } \\
\text { drought }\end{array}$ \\
\hline $\begin{array}{l}\text { Plant species } \\
\text { selection }\end{array}$ & $\begin{array}{l}\text { Drought tolerant species } \\
\text { Quickly germinating species } \\
\text { Species with physical/chemical dormancy }\end{array}$ & LS, LP, SP, SS \\
& Shade tolerant species on southern aspects & SS \\
& Light tolerant species on northern aspects & LS, LP \\
& Annual grasses & LS, LP \\
& Perennial grasses & LS, LP, SP, SS \\
& Trees & SS, SP \\
\hline Planting/seeding & Trees require repeated establishment & LS, LP, SP, SS \\
regime & Annual/perennial grasses are successful after rain events & LS, LP \\
\hline Soil characteristics, SP & LS, LP \\
& Deep topsoil & LS, LP, SP \\
& Amendments of silt/clay & LS, LP \\
& Gentle slopes & LS, LP \\
& Mulching & SS \\
\hline Irrigation method & Regular irrigation & LS, LP \\
& Seasonal irrigation & SS, SP \\
& Critical stage irrigation & LS, LP, SP, SS \\
& Drainage system & LS, LP \\
\hline
\end{tabular}

SS - high recurrence of short term (3 months) severe droughts; SP - high recurrence of short term (3 months) prolonged droughts; LS - high recurrence of long term (12 months) severe droughts; LP - high recurrence of long term (12 months) prolonged droughts.

orgis et al., 2013; Chebbi et al., 2013). Our new term "design droughts", characterised by drought severity-durationfrequency (SDF), is based on the severity of droughts (cumulative negative values of a particular drought; see Fig. 3) as opposed to IDF, which is based on the intensity of the rainfall. Design droughts allow for drought severity, duration and frequency to be considered in order to determine the risk of failure of current mining operations (Mason et al., 2013; Burton et al., 2012), and to design robust ecosystem components in the face of the local climate variability (Audet et al., 2013). Unlike degraded land (in the sense of gradual loss of ecosystem productivity) in post-mining landscapes, most ecosystem components are impacted by mining activities; particularly landform, hydrology, and ecosystem structure (Arnold et al., 2014b). Therefore, successful rehabilitation of post-mining land requires the sensible selection of plant species, as well as planting/seeding regime, soil characteristics, irrigation method, and landform characteristics (Table 3). For example, same vegetation types cannot establish if a drought event exceeds values of specific duration or severity (Arnold et al., 2014a). The recurrence intervals can provide the probability of a drought occurring at this duration or severity, and thus the risk of establishment failure can be assessed. This is important for rehabilitation managers who can conduct a cost-benefit analysis to decide whether the costs of constructing mitigation methods (such as irrigation) are comparable with the costs of potential failure of multiple revegetation attempts.
Together, design rainfalls (IDF) and droughts (SDF) should be the primary determinants of rehabilitation strategies and eventually help guide rehabilitation planning, where environmental conditions have an impact on current mining operations. In accordance with IDF parameters of similar locations across eastern Australia (Audet et al., 2013), temperate and tropical environmental conditions (Table 1) are favourable for rehabilitation, i.e. recurrence intervals of droughts are large (Figs. 6 and 7 and Appendix D). By contrast, re-establishment of ecosystems are prone to failure in arid conditions, where droughts recur more frequently (i.e. low recurrence intervals).

At locations with distinct patterns of winter and summer rainfall, such as Weipa, Cairns, Mount Isa, or the Brigalow Belt, seasonality is the primary determinant of drought occurrence (Table 1). The short-term drought index $\left(\mathrm{RDI}_{3}\right)$ detects most severe and prolonged droughts in tropical Weipa and Cairns (Table 2), where rainfall is low in winter and high in summer. Annually recurring seasonal patterns also explain the low variability of short-term drought severity and duration. In contrast the long-term drought index $\left(\mathrm{SPEI}_{12}\right)$ detects most severe and prolonged droughts in arid Quilpie and Mount Isa, as well as temperate Melbourne (Table 2). Major weather events such as El Niño and La Niña from recent decades coincided with low and high drought indices, respectively (Fig. 4 and Appendix C).

We compared SPI with SPEI or RDI to determine the potential of using SPI (only based on rainfall data) over SPEI 
or RDI (both based on rainfall and evaporation data). This might be of interest for many parts of the world, where evaporation data are unavailable or incomplete and therefore simple rainfall indices are most commonly used. Our analysis revealed that Pearson's $r$ and Kendall's $\tau$ correlations were strong across selected locations (Fig. 5 and Appendix E), indicating the potential of the simple SPI to serve as a surrogate for the more complex RDI and SPEI. For temperate and tropical environments, such as Cairns, Weipa, or Brisbane, the more complex RDI and SPEI can be replaced by the simple SPI if evaporation data is not available (Fig. 5 and Appendix E). By contrast, in arid Bourke, Quilpie, or Mount Isa, correlations between SPI and the more complex indices were weaker, because evaporation plays a critical role in arid climates rather than in tropics and temperate regions. In these arid and water-limited locations (Table 1) we recommend using SPEI and $\mathrm{RDI}^{2}$ and also to conduct intensive monitoring of ecosystem development in relation to empirical weather data to measure evaporation directly, e.g. pan evaporation (Lugato et al., 2013; Clark, 2013), or indirectly, e.g. based on radiative and aerodynamic variables (Allen et al., 1998).

\subsection{SDF curves as an early risk assessment tool}

Risk assessment based on the design rainfall concept is commonly used as a standard tool by engineers to design infrastructure such as storm water drains, flood mitigation levees, or retarding dams (Chebbi et al., 2013; Hailegeorgis et al., 2013). This research paper aims to demonstrate how these concepts can be used for ecosystem rehabilitation, providing a quantitative estimate of ecosystem rehabilitation failure due to water deficit. Traditionally, ecologist and land managers often use the mean annual rainfall as a co-classifier of biogeographic regionalisation. However, annual rainfall alone cannot account for the vulnerability of a site to nondisruptive water supply, the frequency of water limitations, and seasonality (Audet et al., 2013). For example, although mean annual rainfall is lowest in Bourke, the SDF analysis reveals that severe and prolonged droughts occur most frequently in Mount Isa. This is because in Mount Isa on average 23 out of 100 days are with no rainfall, as most of the rainfall occurs in summer as storm events greater than $100 \mathrm{~mm}$ (Table 1) (Bureau of Meteorology, 2013). Ecosystem rehabilitation may fail if management actions are based only on the annual rainfall without considering the nature of drought events (i.e. the rate of recurrence of prolonged and severe droughts) (Table 3).

Quantitatively, risk is the product of the probability of an event occurring and the consequences of an event on assets (Athearn, 1971). In the context of post-mining land rehabilitation, the recurrence intervals quantify the probabil-

\footnotetext{
${ }^{2}$ Note that the definition and quantification of drought are normative. In this regard, our results indicate under what climatic conditions SPEI and RDI can be replaced by SPI, rather than which index is the best one for each location.
}

ity of occurrence of drought events. If the consequences of drought events for ecosystems are known (Wilhite et al., 2007; Williamson et al., 2000) the risk of ecosystem rehabilitation failure can be quantified. Consequences will typically have to be determined in relation to site specific attributes such as plant species, soil, irrigation, etc. (Table 3). Likewise, the consequences can also be related to the costs of rehabilitation. For example, for frequently recurring droughts of high severity and duration, irrigation may be a cost-efficient alternative to repeatedly replanting at a rehabilitation site due to establishment failure. These consequences in relation to severity and duration may be identified from the literature, field trials or be derived from expert opinion. A key aspect of our study is that SDF curves provide the probability of occurrence of drought events with a specific duration and severity.

\subsection{Application of design droughts to rehabilitation planning}

One of the major outcomes of this study is to support land managers and/or rehabilitation practitioners to make fundamental decisions on appropriate management actions in the context of drought frequency. For rehabilitation to be successful in the face of severe and prolonged droughts, there are a range of management domains and management actions that need to be considered in response to recurrence intervals, drought severity, and drought duration (Table 3). These management actions can be categorised into four domains: plant species selection; planting/seeding regime; soil characteristics; and irrigation method.

Meteorological droughts indicate deviations of rainfall and/or evaporation relative to the long-term average. Native climax vegetation, which is well adapted to the local climate, is hardly sensitive to these anomalies. However, within the process of post-mining land rehabilitation, establishment of well-adapted climax vegetation is impossible. In fact, postmining ecosystem rehabilitation is very sensitive to decisions made on the re-established topography and soil characteristics, as well as planting/seeding regimes and irrigation methods (Table 3). In this regard, the frequency of meteorological droughts relative to long-term conditions is the critical driver of these management decisions. For example, seedling establishment might fail under conditions of frequently occurring short-term droughts, even if the absolute rainfall in between droughts is high. Under these conditions, landform and soil need to be restored so that the periods of water limitation can be minimised.

Selection of suitable plant species based on drought type is one of the key management actions for successful rehabilitation. Some management actions can be applied to all drought types (LS, LP, SS, SP in Table 3). These include (i) planting of drought tolerant species (e.g. Acacia spp., Banksia spp., Casuarina spp.) at (ii) northern aspects to address drier conditions that result from higher solar radiation causing increased evaporation (Sternberg and Shoshany, 2001), and 
(iii) planting of perennial grasses (Eragrostis spp., Themeda spp.; Bolger et al., 2005), which may not be affected by longterm water deficits. At locations with frequently recurring long-term (12-monthly timescale) droughts of high severity and durations (LS, LP in Table 3), e.g. in Mount Isa and Quilpie, seeding of species with physical/chemical dormancy may increase the probability of germination during favourable periods (Hilhorst, 1995; Arnold et al., 2014b). Additionally, a southern aspect may require drought tolerant species to increase survival of plant communities (Sternberg and Shoshany, 2001). However, these species need to be shade tolerant as southern aspects get less solar radiation in winter. At locations with frequently recurring short-term (3monthly timescale) droughts of high severity but short duration, with rainfall throughout the year (SS in Table 3), e.g. in Wagga Wagga, annual grasses and seeds with short germination periods may be suitable.

Soil characteristics play a critical role for plant available water and a number of strategies may need to be employed to make soil more favourable to plant establishment. Except for mulching, all soil management actions can be applied to locations with high recurrence of long-term, severe, and prolonged droughts (LS, LP in Table 3), e.g. in Quilpie and Mount Isa. For locations with high recurrence of short-term, and prolonged droughts (SP in Table 3), such as Melbourne, increasing depth of topsoil can increase water holding capacity (Audet et al., 2013; Bot and Benites, 2005). Similarly, by mixing silt and clay soil in the topsoil and reducing slope gradients may facilitate infiltration and increase soil water retention capacity (Audet et al., 2013). For tropical locations with high recurrence of short-term (3-monthly timescale), severe, and prolonged droughts (SS, SP in Table 3), e.g. in Cairns and Weipa, ground cover such as mulch and fast growing vegetation cover (e.g. Buffel grass) may reduce evaporation and maintain soil moisture to facilitate the establishment of drought sensitive and slow growing species (Blum, 1996).

Utilising irrigation methods for specific site characteristics is a cost-effective strategy for any rehabilitation plan. Regular irrigation with proper drainage systems that distributes water is an effective strategy in locations with high recurrence of long-term, severe, and prolonged droughts (LP, LS in Table 3). For locations with high recurrence of short-term, severe, and prolonged droughts (SS, SP in Table 3), with seasonal rainfall (e.g. Brisbane, Sydney, Kingaroy, Brigalow), seasonal irrigation and irrigation at critical stages of plant growth (Blum, 1996), such as during periods of germination, and root or pod development periods are efficient actions to ensure plant survival throughout drought spells.

\subsection{Future research}

The method outlined in this study provides a useful tool for land managers to address site-based climatic conditions. Future research needs to build on this tool, as well as address the limitations of our method based on meteorologi- cal drought indices inferred from point observations. This research may assess: (i) the relationship between meteorological and agricultural drought indices; (ii) regional scale mapping of drought indices; and (iii) the predictive power of design droughts.

While the applied drought indices are robust indicators of meteorological droughts (Mishra and Singh, 2010; Quiring, 2009), they are limited to detecting anomalies from historic rainfall patterns. Soil plays a critical role for any ecosystem development, particularly with regard to ecosystem rehabilitation in post-mining land (Arnold et al., 2013), as soil properties translate rainfall into plant available water (Zhang et al., 2001; Huang et al., 2013). Future drought analysis would benefit from integrating soil properties such as depth, texture, salinity, or organic matter content into drought indices to describe agricultural droughts (Khare et al., 2013; Baldocchi et al., 2004; Woli et al., 2012). Soil texture and depth are critical factors in highly seasonal climates, where soil water storage overcomes periods of water deficit (Prentice et al., 1992; Bot and Benites, 2005). However, using simple and easily accessible meteorological data is a critical step forward to making it easier for mine rehabilitation managers to adopt the concept of using SDF curves as early risk assessment tools.

Although the selected locations can be considered representative of the agro-climatic environments across eastern Australia (Fig. 1), our analysis is strictly valid for the selected point data and therefore site-specific. Future work should not only integrate the above-mentioned soil component but also extend drought analyses across Australia using gridded weather data from the Bureau of Meteorology (2014). Future investigations could assess possible trends in temporal changes of recurrence intervals by dividing historic time series of rainfall and evaporation into subsets and replicate the analysis for each subset (Li et al., 2014; Darshana et al., 2013; Jacobs et al., 2013; Halwatura et al., 2015).

\section{Conclusions}

The study revealed site-specific patterns of recurrence intervals of short-term and long-term droughts across eastern Australia. Severe and prolonged short-term droughts recurred most often in tropical climates and temperate Wagga Wagga, while severe and prolonged short-term droughts recurred most often in arid conditions and temperate Melbourne. Design droughts can be applied to quantify the frequency of drought events - characterised by severity and duration - at different timescales. This is a critical step forward to consider drought in risk assessments for rehabilitation of post-mining ecosystems. Together with design rainfalls, design droughts should be used to assess rehabilitation strategies and ecological management based on drought recurrence intervals, thereby minimising the risk of failure of initial ecosystem establishment due to ignorance of fundamental abiotic and site-specific environmental barriers. 


\section{Appendix A: RDI and SPEI}

\section{A1 RDI}

The standardised $\mathrm{RDI}_{\mathrm{st}}$ is given as

$\operatorname{RDI}_{\mathrm{st}}(k)=\frac{y_{k}-\bar{y}_{k}}{\hat{\sigma}_{k}}$,

with

$$
y_{k}=\ln \frac{\sum_{j=1}^{j=k} P_{j}}{\sum_{j=1}^{j=k} \operatorname{PET}_{j}}
$$

where $\hat{\sigma}$ is the standard deviation, $y_{k}$ is month $k$ of year $y$, $\bar{y}_{k}$ is the arithmetic mean of $y_{k}, \hat{\sigma}_{k}$ is the standard deviation of $y_{k}$, and $P_{j}$ and $\mathrm{PET}_{j}$ are precipitation and potential evapotranspiration for the $j$ th month of the hydrological year, respectively (Tsakiris and Vangelis, 2005).

\section{A2 SPEI}

The SPEI is calculated as

$\mathrm{SPEI}=W-\frac{C_{0}+C_{1} W+C_{2} W^{2}}{1+d_{1} W+d_{2} W^{2}+d_{3} W^{3}}$

with

$W=\sqrt{-2 \ln (P)}$ for $P \leq 0.5$, where $P$ is the probability of exceeding a determined value of the difference between the precipitation and potential evapotranspiration $(P=1-F(x))$. If $P>0.5$, then $P$ is replaced by $1-P$ and the sign of the resultant SPEI is reversed. The constants are $C_{0}=2.515517, C_{1}=0.802853$, $C_{2}=0.010328, \quad d_{1}=1.432788, \quad d_{2}=0.189269, \quad$ and $d_{3}=0.001308$ (Vicente-Serrano et al., 2010).

\section{Appendix B: Mathematical description of Gumbel and} Frank copula (Shiau, 2006)

\section{B1 Gumbel copula}

$$
\begin{gathered}
C(u, v)=\exp \left\{-\left[(-\ln u)^{\theta}+(-\ln v)^{\theta}\right]^{\frac{1}{\theta}}\right\}, \quad \theta \geq 1 \\
c(u, v)=C(u, v) \frac{\left[(-1 \ln u)^{\theta}(-\ln v)^{\theta-1}\right]}{u v}\left[(-1 \ln u)^{\theta}(-\ln v)^{\theta}\right]^{\frac{2}{\theta}-2} \\
\cdot\left\{(\theta-1)\left[(-\ln u)^{\theta}+(-\ln v)^{\theta}\right]^{-\frac{1}{\theta}}+1\right\}
\end{gathered}
$$

\section{B2 Frank copula}

$$
\begin{aligned}
& C(u, v)=-\frac{1}{\theta} \ln \left[1+\frac{\left(e^{-\theta u}-1\right)\left(e^{-\theta v}-1\right)}{e^{-\theta}-1}\right], \quad \theta \neq 0 \\
& c(u, v)=-\frac{\theta e^{-\theta(u+v)}\left(e^{-\theta}-1\right)}{\left[e^{-\theta(u+v)}-e^{-\theta u}-e^{-\theta v}+e^{-\theta}\right]^{2}}
\end{aligned}
$$


Appendix C: Time series of drought indices and major weather event
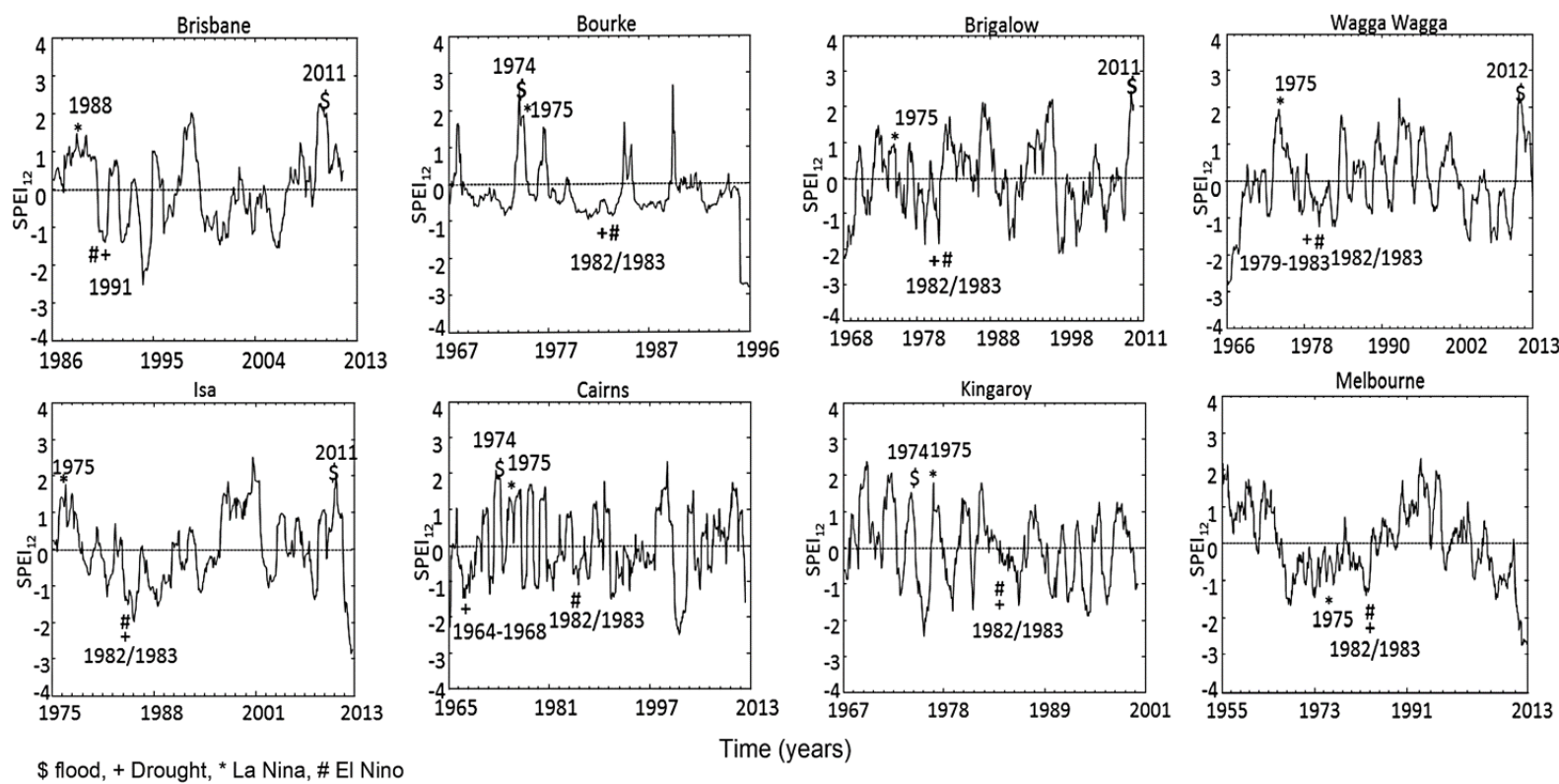

Figure C1. Calculated $\mathrm{SPEI}_{12}$ for selected locations across eastern Australia.
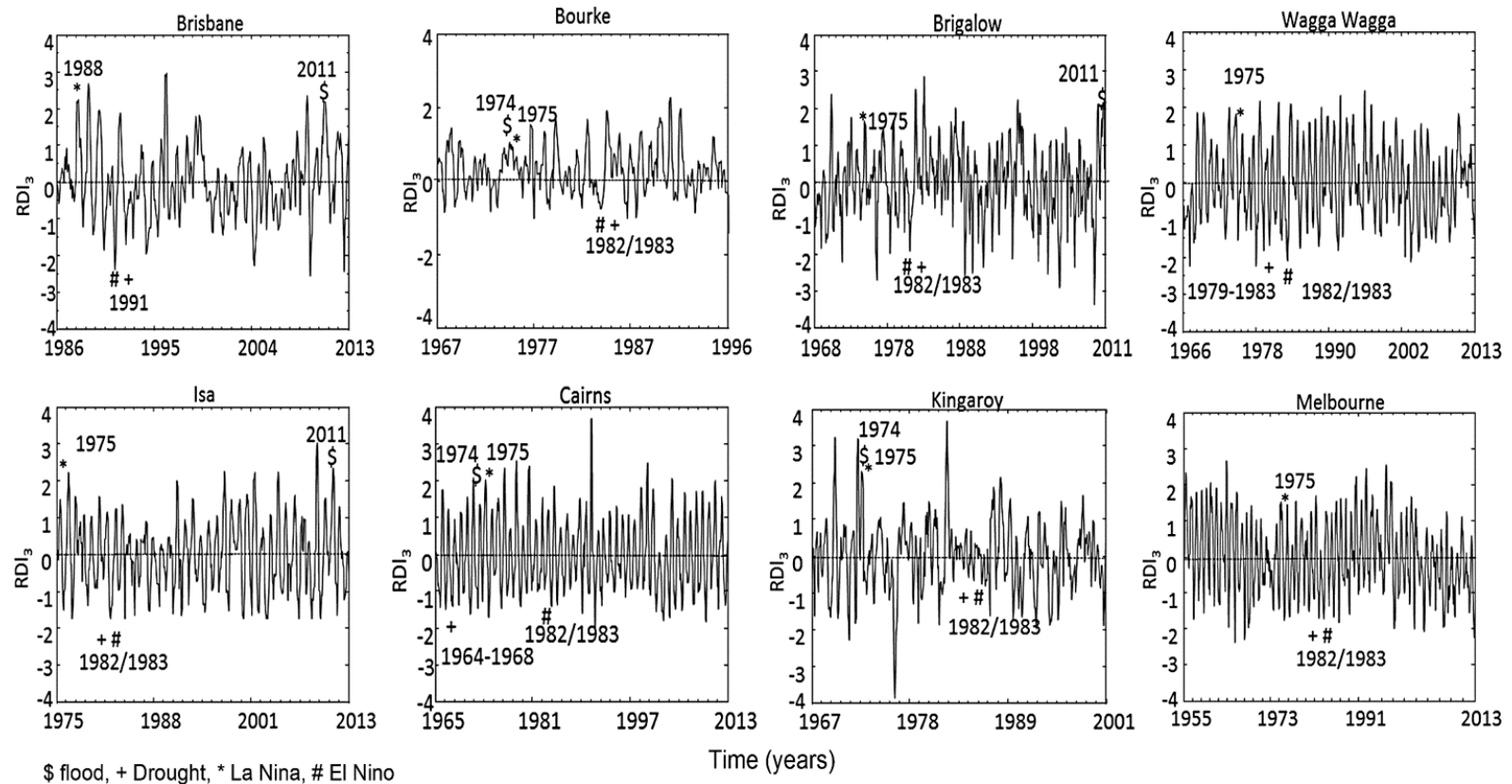

Figure C2. Calculated $\mathrm{RDI}_{3}$ for selected locations across eastern Australia. 
Appendix D: Recurrence intervals of drought events with any severity and duration of interest
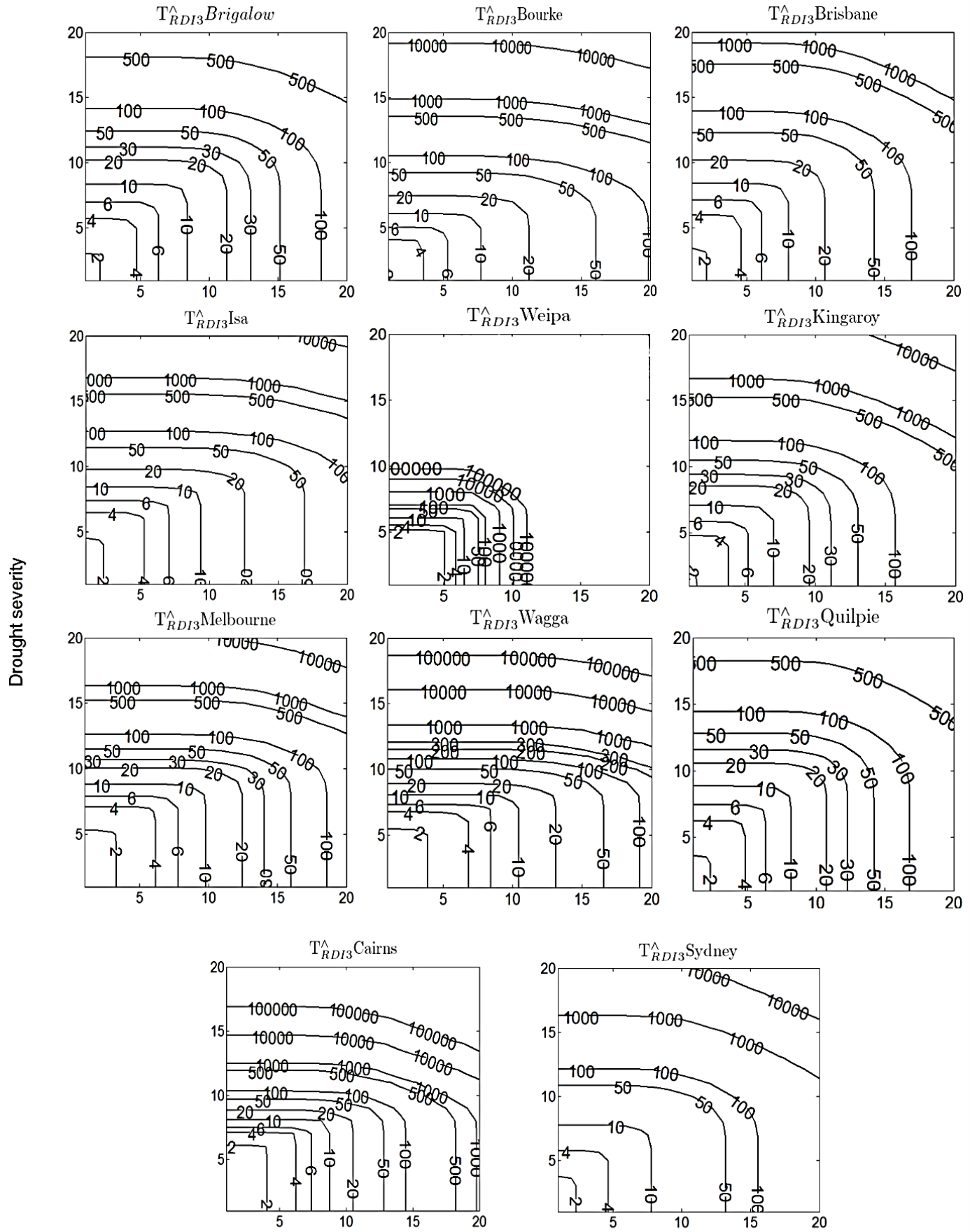

Drought duration (months)

Figure D1. Recurrence intervals $T^{\wedge}$ (years) of drought events with any severity and duration of interest based on $\mathrm{RDI}_{3}$ (short-term) of historical rainfall. 

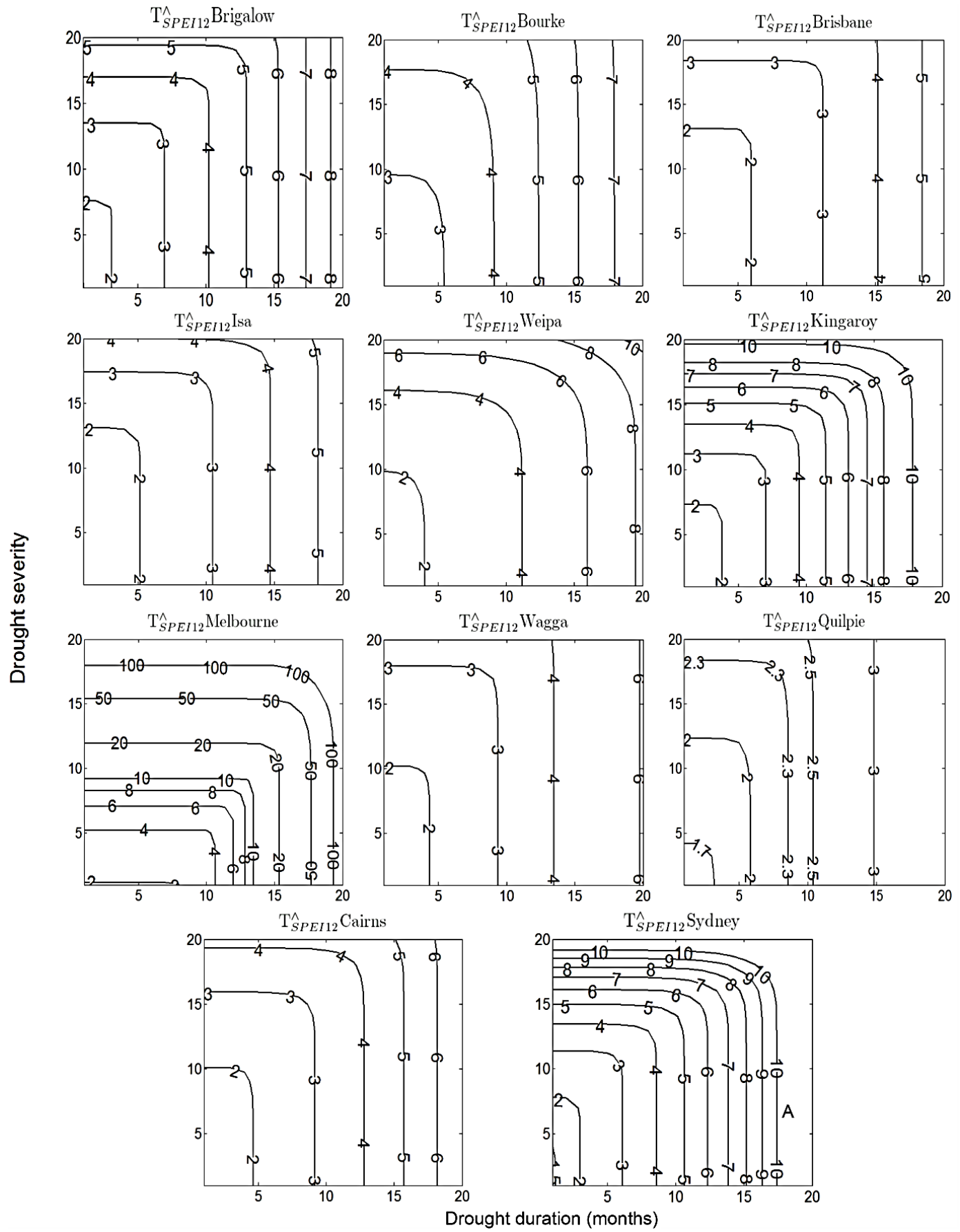

Figure D2. Recurrence intervals $T^{\wedge}$ (years) of drought events with any severity and duration of interest based on $\mathrm{SPEI}_{12}$ (long-term) of historical rainfall. 
Appendix E: Coefficient values of Pearson's $r$ and

Kendall's $\tau$ for $\mathrm{SPI}_{3}$ vs. $\mathrm{RDI}_{3}$, and $\mathrm{SPI}_{12}$ vs. $\mathrm{SPEI}_{12}$

Table E1. Coefficient values of Pearson's $r$ and Kendall's $\tau$ for $\mathrm{SPI}_{3}$ vs. $\mathrm{RDI}_{3}$, and $\mathrm{SPI}_{12}$ vs. $\mathrm{SPEI}_{12}$. Correlations were lowest for arid Bourke and Quilpie (bold values).

\begin{tabular}{lccccc}
\hline \multirow{2}{*}{ Location } & \multicolumn{2}{c}{$\mathrm{SPI}_{3}$ vs. $\mathrm{RDI}_{3}$} & & \multicolumn{2}{c}{$\mathrm{SPI}_{12}$ vs. $\mathrm{SPEI}_{12}$} \\
\cline { 2 - 3 } \cline { 5 - 6 } & Pearson's $r$ & Kendall's $\tau$ & & Pearson's $r$ & Kendall's $\tau$ \\
\hline Weipa & 0.98 & 0.92 & & 0.83 & 0.68 \\
Cairns & 0.98 & 0.90 & & 0.96 & 0.83 \\
Brisbane & 0.81 & 0.62 & & 0.68 & 0.68 \\
Sydney & 0.82 & 0.61 & & 0.90 & 0.71 \\
Melbourne & 0.98 & 0.90 & & 0.82 & 0.70 \\
Kingaroy & 0.77 & 0.54 & & 0.87 & 0.68 \\
Brigalow & 0.90 & 0.71 & & 0.83 & 0.64 \\
Wagga Wagga & 0.69 & 0.68 & & 0.84 & 0.71 \\
Bourke & $\mathbf{0 . 4 3}$ & $\mathbf{0 . 5 4}$ & & $\mathbf{0 . 5 1}$ & $\mathbf{0 . 5 3}$ \\
Quilpie & $\mathbf{0 . 5 7}$ & $\mathbf{0 . 4 0}$ & & $\mathbf{0 . 4 9}$ & $\mathbf{0 . 4 0}$ \\
Mount Isa & 0.78 & 0.60 & & 0.72 & 0.67 \\
\hline
\end{tabular}


Appendix F: $R^{2}$ and $p$ values for fitted cumulative distribution functions and Copula parameters

Table F1. $R^{2}$ and $p$ values for fitted cumulative distribution functions and Copula parameters for the studied sites.

\begin{tabular}{|c|c|c|c|c|c|c|c|c|c|c|c|c|c|c|c|c|}
\hline \multirow[t]{3}{*}{ Station } & \multicolumn{12}{|c|}{ Cumulative distribution functions } & \multicolumn{4}{|c|}{ Copula } \\
\hline & \multicolumn{2}{|c|}{ Exponential } & \multicolumn{2}{|c|}{ Logistic } & \multicolumn{2}{|c|}{ Lognormal } & \multicolumn{2}{|c|}{$\begin{array}{l}\text { Bimodal } \\
\text { lognormal }\end{array}$} & \multicolumn{2}{|c|}{ Gamma } & \multicolumn{2}{|c|}{ Extreme value } & \multicolumn{2}{|c|}{ Gumbel } & \multicolumn{2}{|c|}{ Frank } \\
\hline & $R^{2}$ & $p$ & $R^{2}$ & $p$ & $R^{2}$ & $p$ & $R^{2}$ & $p$ & $R^{2}$ & $p$ & $R^{2}$ & $p$ & $R^{2}$ & $p$ & $R^{2}$ & $p$ \\
\hline Weipa & 0.24 & 0.00 & 0.99 & 0.00 & 0.00 & 0.31 & 0.00 & 0.57 & 0.99 & 0.00 & 0.60 & 0.00 & 0.97 & 0.00 & 1.00 & 0.00 \\
\hline Cairns & 0.00 & 0.20 & 1.00 & 0.00 & 0.00 & 0.52 & 0.00 & 0.68 & 1.00 & 0.00 & 0.53 & 0.00 & 0.98 & 0.00 & 0.99 & 0.00 \\
\hline Brisbane & 0.00 & 0.30 & 1.00 & 0.00 & 0.00 & 0.61 & 0.00 & 0.61 & 0.98 & 0.00 & 0.57 & 0.00 & 0.96 & 0.00 & 0.98 & 0.00 \\
\hline Sydney & 0.31 & 0.00 & 0.99 & 0.00 & 0.00 & 0.64 & 0.00 & 0.52 & 1.00 & 0.00 & 0.55 & 0.00 & 0.97 & 0.00 & 1.00 & 0.00 \\
\hline Melbourne & 0.25 & 0.00 & 0.99 & 0.00 & 0.00 & 0.63 & 0.00 & 0.64 & 0.99 & 0.00 & 0.42 & 0.00 & 0.96 & 0.00 & 1.00 & 0.00 \\
\hline Kingaroy & 0.00 & 0.08 & 1.00 & 0.00 & 0.00 & 0.42 & 0.00 & 0.43 & 0.99 & 0.00 & 0.68 & 0.00 & 0.98 & 0.00 & 0.99 & 0.00 \\
\hline Brigalow & 0.00 & 0.06 & 0.96 & 0.00 & 0.00 & 0.64 & 0.00 & 0.26 & 0.99 & 0.00 & 0.62 & 0.00 & 0.96 & 0.00 & 1.00 & 0.00 \\
\hline Wagga Wagga & 0.00 & 0.15 & 0.96 & 0.00 & 0.00 & 0.61 & 0.00 & 0.54 & 0.91 & 0.00 & 0.43 & 0.00 & 0.97 & 0.00 & 1.00 & 0.00 \\
\hline Bourke & 0.00 & 0.21 & 0.94 & 0.00 & 0.00 & 0.31 & 0.00 & 0.34 & 0.98 & 0.00 & 0.62 & 0.00 & 0.95 & 0.00 & 1.00 & 0.00 \\
\hline Quilpie & 0.12 & 0.00 & 0.98 & 0.00 & 0.00 & 0.15 & 0.00 & 0.29 & 0.99 & 0.00 & 0.53 & 0.00 & 0.96 & 0.00 & 0.99 & 0.00 \\
\hline Mount Isa & 0.20 & 0.00 & 0.99 & 0.00 & 0.00 & 0.56 & 0.00 & 0.46 & 0.97 & 0.00 & 0.68 & 0.00 & 0.95 & 0.00 & 1.00 & 0.00 \\
\hline
\end{tabular}


Acknowledgements. This study was made possible by the University of Queensland Post-doctoral Fellowship scheme and Early Career Research Grant awarded to S. Arnold, as well as the International Postgraduate Research Scholarship awarded to D. Halwatura. We thank Tanja Giebner for her dedicated work on deriving the RDI for selected locations. Further, we thank David Doley and Patrick Audet for critical discussions and seven anonymous reviewers for their constructive comments.

Edited by: N. Ursino

\section{References}

Allen, R. G., Pereira, L. S., Raes, D., and Smith, M.: Crop evapotranspiration-Guidelines for computing crop water requirements-FAO Irrigation and drainage paper 56, FAO, Rome, Italy, 300 pp., 1998.

Anderegg, L. D., Anderegg, W. R., and Berry, J. A.: Not all droughts are created equal: translating meteorological drought into woody plant mortality, Tree Physiol., 33, 672-683, 2013.

Arnold, S. , Audet, P. , Doley, D., and Baumgartl, T.: Hydropedology and Ecohydrology of the Brigalow Belt, Australia: Opportunities for Ecosystem Rehabilitation in Semiarid Environments, Gsvadzone, 12, doi:10.2136/vzj2013.03.0052, 2013.

Arnold, S., Kailichova, Y., and Baumgartl, T.: Germination of Acacia harpophylla (Brigalow) seeds in relation to soil water potential: implications for rehabilitation of a threatened ecosystem, Peer J., 2, e268, doi:10.7717/peerj.268, 2014a.

Arnold, S. , Kailichova, Y. , Knauer, J., Ruthsatz, A. D., and Baumgartl, T.: Effects of soil water potential on germination of codominant Brigalow species: Implications for rehabilitation of water-limited ecosystems in the Brigalow Belt bioregion, Ecol. Eng., 70, 35-42, doi:10.1016/j.ecoleng.2014.04.015, 2014b.

Athearn, J. L.: What is Risk?, J. Risk Insur., 38, 639-645, doi:10.2307/251578, 1971.

Audet, P., Arnold, S., Lechner, A. M., Mulligan, D. R., and Baumgartl, T.: Climate suitability estimates offer insight into fundamental revegetation challenges among post-mining rehabilitated landscapes in eastern Australia, Biogeosciences Discuss., 9, 18545-18569, doi:10.5194/bgd-9-18545-2012, 2012.

Audet, P., Arnold, S., Lechner, A. M., and Baumgartl, T.: Sitespecific climate analysis elucidates revegetation challenges for post-mining landscapes in eastern Australia, Biogeosciences, 10, 6545-6557, doi:10.5194/bg-10-6545-2013, 2013.

Baldocchi, D. D. , Xu, L., and Kiang, N.: How plant functionaltype, weather, seasonal drought, and soil physical properties alter water and energy fluxes of an oak-grass savanna and an annual grassland, Agr. Forest Meteorol., 123, 13-39, doi:10.1016/j.agrformet.2003.11.006, 2004.

Banimahd, S. and Khalili, D.: Factors influencing markov chains predictability characteristics, utilizing SPI, RDI, EDI and SPEI drought indices in different climatic zones, Water Resour. Manage., 27, 3911-3928, doi:10.1007/s11269-013-0387-z, 2013.

Bell, L. C.: Establishment of native ecosystems after mining Australian experience across diverse biogeographic zones, Ecol. Eng., 17, 179-186, doi:10.1016/S0925-8574(00)00157-9, 2001.

Blum, A.: Crop responses to drought and the interpretation of adaptation, Plant Growth Regul., 20, 135-148, 1996.
Bolger, T. P., Rivelli, A. R., and Garden, D. L.: Drought resistance of native and introduced perennial grasses of south-eastern Australia, Aust. J. Agr. Res., 56, 1261-1267, doi:10.1071/AR05075, 2005.

Bot, A. and Benites, J.: The importance of soil organic matter: key to drought-resistant soil and sustained food and production, FAO, Rome, Italy, 2005.

Brouwers, N., Matusick, G. , Ruthrof, K. , Lyons, T., and Hardy, G.: Landscape-scale assessment of tree crown dieback following extreme drought and heat in a Mediterranean eucalypt forest ecosystem, Landscape Ecol., 28, 69-80, doi:10.1007/s10980012-9815-3, 2013.

Bureau of Meteorology: Climate data, http://www.bom.gov.au/ climate/data/, last access: April 2013.

Bureau of Meteorology: Australian water availability project 2014, http://www.bom.gov.au/jsp/awap/, last access: January 2014.

Burton, M., Jasmine Zahedi, S., and White, B.: Public preferences for timeliness and quality of mine site rehabilitation. The case of bauxite mining in Western Australia, Resources Policy, 37, 1-9, 2012.

Chebbi, A., Bargaoui, Z. K., and da Conceição Cunha, M.: Development of a method of robust rain gauge network optimization based on intensity-duration-frequency results, Hydrol. Earth Syst. Sci., 17, 4259-4268, doi:10.5194/hess-17-42592013, 2013.

Clark, C.: Measurements of actual and pan evaporation in the upper Brue catchment UK: the first 25 years, Weather, 68, 200-208, doi:10.1002/wea.2090, 2013.

Craven, D., Hall, J. S., Ashton, M. S., and Berlyn, G. P.: Wateruse efficiency and whole-plant performance of nine tropical tree species at two sites with contrasting water availability in Panama, Trees-Struct. Funct., 27, 639-653, doi:10.1007/s00468012-0818-0, 2013.

Darshana, Pandey, A., and Pandey, R. P.: Analysing trends in reference evapotranspiration and weather variables in the Tons River Basin in Central India, Stoch. Environ. Res. Risk Assess., 27, 1407-1421, doi:10.1007/s00477-012-0677-7, 2013.

Doley, D. and Audet, P.: Adopting novel ecosystems as suitable rehabilitation alternatives for former mine sites, Ecol. Process., 2, 1-11, doi:10.1186/2192-1709-2-22, 2013.

Doley, D., Audet, P., and Mulligan, D. R.: Examining the Australian context for post-mined land rehabilitation: Reconciling a paradigm for the development of natural and novel ecosystems among post-disturbance landscapes, Agr. Ecosyst. Environ., 163, 85-93, doi:10.1016/j.agee.2012.04.022, 2012.

Egidijus, R., Edvinas, S., Vladimir, K., Justas, K., Gintaras, V., and Aliaksandr, P.: Dynamics of meteorological and hydrological droughts in the Neman river basin, Environ. Res. Lett., 8, 045014, doi:10.1088/1748-9326/8/4/045014, 2013.

Engelbrecht, B. M., Comita, L. S., Condit, R., Kursar, T. A., Tyree, M. T., Turner, B. L., and Hubbell, S. P.: Drought sensitivity shapes species distribution patterns in tropical forests, Nature, 447, 80-82, 2007.

Ganguli, P. and Reddy, M. J.: Risk assessment of droughts in Gujarat using bivariate Copulas, Water Resour. Manage., 26, 33013327, 2012.

Gardner, J. H. and Bell, D. T.: Bauxite mining restoration by Alcoa World Alumina Australia in Western Australia: social, po- 
litical, historical, and environmental contexts, Restor. Ecol., 15, S3-S10, doi:10.1111/j.1526-100X.2007.00287.x, 2007.

Guttman, N. B.: Accepting the Standardized Precipitation Index: a calculation algorithm, J. Am. Water Resour. Assoc., 35, 311322, 1999.

Hailegeorgis, T. T., Thorolfsson, S. T., and Alfredsen, K.: Regional frequency analysis of extreme precipitation with consideration of uncertainties to update IDF curves for the city of Trondheim, J. Hydrol., 498, 305-318, doi:10.1016/j.jhydrol.2013.06.019, 2013.

Halwatura, D., Lechner, A. M., and Arnold, S.: Design droughts: A new planning tool for ecosystem rehabilitation, Int. J. Geomate, 8, 1138-1142, 2015.

Heim, R. R.: A review of twentieth-century drought indices used in the United States, B. Am. Meteorol. Soc., 83, 1149-1165, 2002.

Hilhorst, H. W.: A critical update on seed dormancy, I. Primary dormancy, Seed Sci. Res., 5, 61-73, 1995.

Hinz, C., McGrath, G., and Hearman, A.: Towards a climate based risk assessment of land rehabilitation, 1st International Seminar on Mine Closure, Australian Centre for Geomechanics, Perth, 407-416, 2006.

Hodgkinson, J. H., Littleboy, A., Howden, M., Moffat, K., and Loechel, B.: Climate adaptation in the Australian mining and exploration industries, CSIRO Climate Adaptation National Research Flagship, 1921605812 - working paper No. 5, http:// www.csiro.au/resources/CAF-working-papers.html (last access: May 2014), 2010.

Hu, Y.-M., Liang, Z.-M., Liu, Y.-W., Wang, J., Yao, L., and Ning, Y.: Uncertainty analysis of SPI calculation and drought assessment based on the application of Bootstrap, Int. J. Climatol., doi:10.1002/joc.4091, in press, 2014.

Huang, M., Barbour, S. L., Elshorbagy, A., Zettl, J., and Si, B. C.: Effects of variably layered coarse textured soils on plant available water and forest productivity, in: Four decades of progress in monitoring and modeling of processes in the soilplant-atmosphere system: Applications and challenges, edited by: Romano, N., Durso, G., Severino, G., Chirico, G. B., and Palladino, M., Procedia Environmental Sciences, Elsevier Science Bv, Amsterdam, 148-157, 2013.

Hutchinson, M. F., McIntyre, S., Hobbs, R. J., Stein, J. L., Garnett, S., and Kinloch, J.: Integrating a global agro-climatic classification with bioregional boundaries in Australia, Global Ecol. Biogeogr., 14, 197-212, 2005.

Jacobs, S. J., Pezza, A. B., Barras, V., Bye, J., and Vihma, T.: An analysis of the meteorological variables leading to apparent temperature in Australia: Present climate, trends, and global warming simulations, Global Planet. Change, 107, 145-156, doi:10.1016/j.gloplacha.2013.05.009, 2013.

Jahantab, E., Javdani, Z., Bahari, A., Bahrami, S., and Mehrabi, A.: Effect of priming treatments on seed germination percentage and rate in the early stages of triticale plants grown under drought stress conditions, Int. J. Agr. Crop Sci., 5, 1909-1917, 2013.

Joe, H.: Multivariate models and dependence concepts, Chapman \& Hall, London, 1997.

Jongen, M. , Unger, S., Fangueiro, D., Cerasoli, S., Silva, J. M. N., and Pereira, J. S.: Resilience of montado understorey to experimental precipitation variability fails under severe natural drought, Agr. Ecosyst. Environ., 178, 18-30, doi:10.1016/j.agee.2013.06.014, 2013.
Khalili, D., Farnoud, T., Jamshidi, H., Kamgar-Haghighi, A. A., and Zand-Parsa, S.: Comparability analyses of the SPI and RDI meteorological drought indices in different climatic zones, Water Resour. Manage., 25, 1737-1757, 2011.

Khare, Y. P., Martinez, C. J., and Munoz-Carpena, R.: Parameter variability and drought models: A study using the Agricultural Reference Index for Drought (ARID), Agron. J., 105, 14171432, doi:10.2134/agronj2013.0167, 2013.

Khedun, C. P., Chowdhary, H., Mishra, A. K., Giardino, J. R., and Singh, V. P.: Water Deficit Duration and Severity Analysis Based on Runoff Derived from Noah Land Surface Model, J. Hydrol. Eng., 18, 817-833, 2013.

Kim, D.-W., Byun, H.-R., and Choi, K.-S.: Evaluation, modification, and application of the Effective Drought Index to 200Year drought climatology of Seoul, Korea, J. Hydrol., 378, 1-12, doi:10.1016/j.jhydrol.2009.08.021, 2009.

Kuo, C. C., Gan, T. Y., and Chan, S.: Regional Intensity-DurationFrequency curves derived from Ensemble Empirical Mode Decomposition and Scaling Property, J. Hydrol. Eng., 18, 66-74, doi:10.1061/(asce)he.1943-5584.0000612, 2013.

Kuster, T., Arend, M., Bleuler, P., Günthardt-Goerg, M., and Schulin, R.: Water regime and growth of young oak stands subjected to air-warming and drought on two different forest soils in a model ecosystem experiment, Plant Biol., 15, 138-147, 2013.

Lee, J. H. and Kim, C. J.: A multimodel assessment of the climate change effect on the drought severity-durationfrequency relationship, Hydrol. Process., 27, 2800-2813, doi:10.1002/hyp.9390, 2012.

Lee, T., Modarres, R., and Ouarda, T. B. M. J.: Data-based analysis of bivariate copula tail dependence for drought duration and severity, Hydrol. Process., 27, 1454-1463, doi:10.1002/Hyp.9233, 2013.

Li, Z., Chen, Y. N., Yang, J., and Wang, Y.: Potential evapotranspiration and its attribution over the past 50 years in the arid region of Northwest China, Hydrol. Process., 28, 1025-1031, 2014.

Livada, I. and Assimakopoulos, V. D.: Spatial and temporal analysis of drought in greece using the Standardized Precipitation Index (SPI), Theor. Appl. Climatol., 89, 143-153, doi:10.1007/s00704005-0227-z, 2007.

Lloret, F.: Vulnerability and resilience of forest ecosystems to extreme drought episodes, Ecosistemas, 21, 85-90, 2012.

Loaiciga, H. and Mariño, M.: Recurrence interval of geophysical events, J. Water Resour. Plan. Manage., 117, 367-382, doi:10.1061/(ASCE)0733-9496(1991)117:3(367), 1991.

Lugato, E., Alberti, G., Gioli, B., Kaplan, J. O., Peressotti, A., and Miglietta, F.: Long-term pan evaporation observations as a resource to understand the water cycle trend: case studies from Australia, Hydrolog. Sci. J., 58, 1287-1296, doi:10.1080/02626667.2013.813947, 2013.

Mariotte, P., Vandenberghe, C., Kardol, P., Hagedorn, F., and Buttler, A.: Subordinate plant species enhance community resistance against drought in semi-natural grasslands, J. Ecol., 101, 763773, doi:10.1111/1365-2745.12064, 2013.

Mason, L., Unger, C., Lederwasch, A., Razian, H., Wynne, L., and Giurco, D.: Adapting to climate risks and extreme weather: A guide for mining and minerals industry professionals, National Climate Change Adaptation Research Facility, Gold Coast, 76 pp., 2013. 
McKee, T. B., Doesken, N. J., and Kleist, J.: The relationship of drought frequency and duration to time scales, Proceedings of the 8th Conference on Applied Climatology, Anaheim, California, 179-183, 1993.

Mirabbasi, R., Fakheri-Far, A., and Dinpashoh, Y.: Bivariate drought frequency analysis using the copula method, Theor. Appl. Climatol., 108, 191-206, 2012.

Mishra, A. K. and Singh, V. P.: A review of drought concepts, J. Hydrol., 391, 202-216, 2010.

Murphy, B. F. and Timbal, B.: A review of recent climate variability and climate change in southeastern Australia, Int. J. Climatol., 28, 859-879, doi:10.1002/joc.1627, 2008.

Myers, N., Mittermeier, R. A., Mittermeier, C. G., Da Fonseca, G. A., and Kent, J.: Biodiversity hotspots for conservation priorities, Nature, 403, 853-858, 2000.

National Drought Mitigation Cente-Interpretation of Standardized Precipitation Index Maps: http://drought.unl.edu/ MonitoringTools/ClimateDivisionSPI/Interpretation.aspx, last access: January 2014.

Nefzaoui, A. and Ben Salem, H.: Cacti: Efficient tool for rangeland rehabilitation, drought mitigation and to combat desertification, in: Proceedings of the Fourth International Congress on Cactus Pear and Cochineal, edited by: Nefzaoui, A. and Inglese, P., Acta Horticulturae, 581, 295-315, 2002.

Paulo, A. A., Rosa, R. D., and Pereira, L. S.: Climate trends and behaviour of drought indices based on precipitation and evapotranspiration in Portugal, Nat. Hazards Earth Syst. Sci., 12, 14811491, doi:10.5194/nhess-12-1481-2012, 2012.

Peel, M. C., Finlayson, B. L., and McMahon, T. A.: Updated world map of the Köppen-Geiger climate classification, Hydrol. Earth Syst. Sci., 11, 1633-1644, doi:10.5194/hess-11-16332007, 2007.

Prentice, I. C., Cramer, W., Harrison, S. P., Leemans, R., Monserud, R. A., and Solomon, A. M.: Special Paper: A global biome model based on plant physiology and dominance, soil properties and climate, J. Biogeogr., 19, 117-134, doi:10.2307/2845499, 1992.

Quiring, S. M.: Monitoring drought: An evaluation of meteorological drought indices, Geogr. Compass, 3, 64-88, doi:10.1111/j.1749-8198.2008.00207.x, 2009.

Reddy, M. J. and Ganguli, P.: Application of copulas for derivation of drought severity-duration-frequency curves, Hydrol. Process., 26, 1672-1685, doi:10.1002/hyp.8287, 2012.

Ruffault, J., Martin-StPaul, N., Rambal, S., and Mouillot, F.: Differential regional responses in drought length, intensity and timing to recent climate changes in a Mediterranean forested ecosystem, Climatic Change, 117, 103-117, doi:10.1007/s10584-012-0559$5,2013$.

Shi, Z., Thomey, M. L., Mowll, W., Litvak, M., Brunsell, N. A., Collins, S. L., Pockman, W. T., Smith, M. D., Knapp, A. K., and Luo, Y.: Differential effects of extreme drought on production and respiration: synthesis and modeling analysis, Biogeosciences, 11, 621-633, doi:10.5194/bg-11-621-2014, 2014.

Shiau, J. T.: Fitting drought duration and severity with twodimensional Copulas, Water Resour. Manage., 20, 795-815, 2006.

Shiau, J. T. and Modarres, R.: Copula-based drought severityduration-frequency analysis in Iran, Meteorol. Appl., 16, 481489, doi:10.1002/met.145, 2009.
Shiau, J.-T., Feng, S., and Nadarajah, S.: Assessment of hydrological droughts for the Yellow River, China, using copulas, Hydrol. Process., 21, 2157-2163, doi:10.1002/hyp.6400, 2007.

Shiau, J.-T., Modarres, R., and Nadarajah, S.: Assessing multi-site drought connections in Iran using empirical Copula, Environ. Model. Assess., 17, 469-482, doi:10.1007/s10666-012-9318-2, 2012.

Sklar, M.: Fonctions de répartition à $\mathrm{n}$ dimensions et leurs marges, Université Paris, Paris, 229-231, 1959.

Smithers, J., Pegram, G., and Schulze, R.: Design rainfall estimation in South Africa using Bartlett-Lewis rectangular pulse rainfall models, J. Hydrol., 258, 83-99, 2002.

Spinoni, J., Antofie, T., Barbosa, P., Bihari, Z., Lakatos, M., Szalai, S., Szentimrey, T., and Vogt, J.: An overview of drought events in the Carpathian Region in 1961-2010, Adv. Sci. Res., 10, 21-32, doi:10.5194/asr-10-21-2013, 2013.

Sternberg, M. and Shoshany, M.: Influence of slope aspect on Mediterranean woody formations: Comparison of a semiarid and an arid site in Israel, Ecol. Res., 16, 335-345, doi:10.1046/j.1440-1703.2001.00393.x, 2001.

Todisco, F., Mannocchi, F., and Vergni, L.: Severity-durationfrequency curves in the mitigation of drought impact: an agricultural case study, Nat. Hazards, 65, 1863-1881, doi:10.1007/s11069-012-0446-4, 2013.

Tsakiris, G.: Meteorological drought assessment, European Research Program MEDROPLAN, Mediterranean Drought Preparedness and Mitigation Planning, Zaragoza, Spain, 2004,

Tsakiris, G. and Vangelis, H.: Establishing a drought index incorporating evapotranspiration, European Water, 9/10, 3-11, 2005.

Tsakiris, G., Pangalou, D., and Vangelis, H.: Regional drought assessment based on the Reconnaissance Drought Index (RDI), Water Resour. Manage., 21, 821-833, 2007.

Unep, N. M. and Thomas, D.: World Atlas of Desertification, Edward Arnold, London, 15-45, 1992.

Vangelis, H., Tigkas, D., and Tsakiris, G.: The effect of PET method on Reconnaissance Drought Index (RDI) calculation, J. Arid Environ., 88, 130-140, doi:10.1016/j.jaridenv.2012.07.020, 2013.

Vargas, R., Sonnentag, O., Abramowitz, G., Carrara, A., Chen, J. M., Ciais, P., Correia, A., Keenan, T. F., Kobayashi, H., and Ourcival, J.-M.: Drought influences the accuracy of simulated ecosystem fluxes: A model-data meta-analysis for Mediterranean Oak Woodlands, Ecosystems, 16, 749-764, 2013.

Vicente-Serrano, S. M., Beguería, S., and López-Moreno, J. I.: A multiscalar drought index sensitive to global warming: The Standardized Precipitation Evapotranspiration Index, J. Climate, 23, 1696-1718, doi:10.1175/2009JCLI2909.1, 2010.

Vicente-Serrano, S. M., Gouveia, C., Camarero, J. J., Beguería, S., Trigo, R., López-Moreno, J. I., Azorín-Molina, C., Pasho, E., Lorenzo-Lacruz, J., Revuelto, J., Morán-Tejeda, E., and Sanchez-Lorenzo, A.: Response of vegetation to drought timescales across global land biomes, P. Natl. Acad. Sci., 110, 52-57, doi:10.1073/pnas.1207068110, 2013.

Wilhite, D. A., Svoboda, M. D., and Hayes, M. J.: Understanding the complex impacts of drought: a key to enhancing drought mitigation and preparedness, Water Resour. Manage., 21, 763-774, 2007.

Williams, J., Hook, R., and Hamblin, A.: Agro-ecological regions of Australia methodology for their derivation and key issues in 
resource management, CSIRO Land \& Water, Canberra, ACT, 2002.

Williamson, G. B., Laurance, W. F., Oliveira, A. A., Delamônica, P., Gascon, C., Lovejoy, T. E., and Pohl, L.: Amazonian tree mortality during the 1997 El Nino drought, Conserv. Biol., 14, 15381542,2000

Woli, P., Jones, J. W., Ingram, K. T., and Fraisse, C. W.: Agricultural reference index for drought (ARID), Agron. J., 104, 287-300, 2012.

Wong, G., Lambert, M. F., Leonard, M., and Metcalfe, A. V.: Drought analysis using trivariate Copulas conditional on climatic states, J. Hydrol. Eng., 15, 129-141, 2010.

Woodhams, F., Southwell, D., Bruce, S., Barnes, B., Appleton, H., Rickards, J., Walcott, J., Hug, B., Whittle, L., and Ahammad, H.: Carbon Farming Initiative: A proposed common practice framework for assessing additionality, Canberra, August 2012.

Yoo, J., Kim, U., and Kim, T.-W.: Bivariate drought frequency curves and confidence intervals: a case study using monthly rainfall generation, Stoch. Environ. Res. Risk Assess., 27, 285-295, 2013.
Zarch, M. A. A., Malekinezhad, H., Mobin, M. H., Dastorani, M. T., and Kousari, M. R.: Drought monitoring by reconnaissance drought index (RDI) in Iran, Water Resour. Manage., 25, 34853504, 2011.

Zargar, A., Sadiq, R., Naser, B., and Khan, F. I.: A review of drought indices, Environ. Rev., 19, 333-349, 2011.

Zhang, A. and Jia, G.: Monitoring meteorological drought in semiarid regions using multi-sensor microwave remote sensing data, Remote Sens. Environ., 134, 12-23, doi:10.1016/j.rse.2013.02.023, 2013.

Zhang, L., Dawes, W. R., and Walker, G. R.: Response of mean annual evapotranspiration to vegetation changes at catchment scale, Water Resour. Res., 37, 701-708, doi:10.1029/2000WR900325, 2001.

Zhang, Q., Chen, Y. D., Chen, X., and Li, J.: Copula-based analysis of hydrological extremes and implications of hydrological behaviors in the Pearl River basin, China, J. Hydrol. Eng., 16, 598-607, 2011. 